\title{
O Quadro Lógico: um método para planejar e gerenciar mudanças
}

\section{Histórico ${ }^{1}$}

O Quadro Lógico (QL) surgiu no contexto da cooperação internacional de apoio ao desenvolvimento. Em meados dos anos 60, a Agência Americana para o Desenvolvimento Internacional/United States Agency for International Development (USAID) constatou que era muito difícil para os projetos de cooperação internacional mostrar a sua efetividade. Uma análise de uma série de projetos deste tipo revelou que:

- o planejamento era pouco preciso. Objetivos, atividades dos projetos e o êxito esperado não estavam claramente relacionados;

- a responsabilidade para o gerenciamento não era clara;

- pelas razões acima mencionadas, as avaliações causaram mais desentendimento do que medidas construtivas para melhorar os projetos.

$\mathrm{Na}$ tentativa de superar esses problemas, a USAID contratou os consultores Rosenberg, Lawrence e Posner que, fundamentando-se em diversos métodos do MBO / Management by Objectives (Gerenciamento por Objetivos) $)^{2}$, elaboraram entre 1969/70 uma metodologia chamada LFA/ Logical Framework Approach (Enfoque Quadro Lógico) ${ }^{3}$. Nos anos seguintes, a metodologia LFA foi sucessivamente revisada e aprimorada, e, em 1982, uma série de organizações internacionais ou internacionalmente atuantes estavam aplicando-a, entre elas, além da USAID, o PNUD (Programa das Nações Unidas para o Desenvolvimento), a CIDA (Cooperação Técnica Canadense) e a ILO (Organização Internacional para o Trabalho).

Peter Pfeiffer é doutor em Sociologia e Planejamento Urbano e mestre em Sociologia de Desenvolvimento pela Universidade Livre de Berlim, Alemanha. Profissional em Gerenciamento de Projetos pelo Project Management Institute, EUA. Consultor em Gerenciamento de Programas e Projetos 
Nessa época, a Cooperação Técnica Alemã estava em busca de instrumentos e métodos para melhorar o seu desempenho, já que a cobrança pública para demonstrar eficiência, do Parlamento e dos contribuintes estava crescendo.

A partir de 1975, o Ministério Federal da Alemanha, responsável pela cooperação com os países em desenvolvimento, o BMZ e a Agência Alemã de Cooperação Técnica (GTZ), em busca de instrumentos e métodos para melhorar o seu desempenho também passaram a aplicar o LFA em alguns projetos. Animados pelos resultados positivos alcançados, a GTZ contratou, como consultor, um dos autores da metodologia para assessorar uma adaptação do LFA às necessidades específicas da Cooperação Técnica Alemã. $\mathrm{O}$ desafio era o de integrar dois enfoques diferentes: a preocupação com as funções de controle do ministério e a criação de um espaço maior para o trabalho em equipes e para a participação dos diversos interessados num projeto da GTZ. O resultado foi o método ZOPP / Zielorientierte Projektplanung (Planejamento de Projeto Orientado para Objetivos).

Assim, desde os anos 90, praticamente todas as organizações no âmbito da cooperação internacional utilizam o instrumento QL, e muitas adotaram também o processo do enfoque, que passou a ser mais conhecido como ZOPP. A inovação do ZOPP em relação ao LFA é que o método ZOPP utiliza o instrumento de forma participativa. Para isso são aplicadas técnicas de trabalho chamadas moderação (também conhecida como facilitação), que permitem uma maior compreensão dos conteúdos trabalhados, especialmente por meio da visualização em workshops e, com isso, uma melhor comunicação entre os envolvidos. O produto principal deste workshop é um QL, além de outras informações relevantes para o gerenciamento do projeto ${ }^{4}$.

A justificativa para essa inovação encontra-se na concepção de que uma efetiva participação é facilitada por uma boa comunicação. $\mathrm{E}$, se a participação funciona, as decisões são mais facilmente compreendidas e compartilhadas, o que, por sua vez, leva a um compromisso maior com o projeto. Com mais compromisso e mais envolvimento os resultados tendem a ser melhores e o alcance dos objetivos se torna mais provável. Tanto ganham com isso as organizações responsáveis pelo projeto como os usuários finais dos benefícios que se espera dele.

\section{Conceitos básicos e estrutura do Quadro Lógico}

O QL é uma matriz ${ }^{5}$ que é elaborada sucessivamente num processo de estruturação daqueles elementos considerados os mais importantes 
de um projeto e que permitem a sua apresentação sistemática, lógica e sucinta. $\mathrm{O}$ que sempre tem que anteceder o planejamento de um projeto é uma análise do que se deseja mudar com a intervenção, de modo geral, uma situação-problema ${ }^{6}$.

É importante destacar que o QL não é um plano completo de um projeto. Trata-se apenas de um resumo do plano de intervenção, que fornece respostas basicamente às seguintes perguntas:

- Por que o projeto deve ser realizado?

- Qual é o seu propósito e quais as mudanças a serem alcançadas?

- Como se pretende produzir melhorias?

- Quais as condições externas que influenciam o alcance dos resultados e dos seus efeitos?

- Como é possível identificar o alcance das melhorias e mudanças?

Em outras palavras: com a aplicação do enfoque QL, pretende-se definir e mostrar o êxito de um projeto já na fase do seu planejamento. Na prática, definir o êxito de um projeto é um desafio bastante ambicioso, já que na literatura especializada não existe clareza ou unanimidade sobre como definir o êxito de um projeto (Baccarini,1999:25).

Mas, exatamente porque a cooperação internacional de desenvolvimento é um terreno muito difícil, procurou-se instrumentos que possam facilitar as decisões sobre projetos. Muitos países em desenvolvimento são caraterizados por tantos problemas óbvios que a apresentação de justificativas para a solicitação de apoio a projetos não é difícil. No entanto, levando em consideração a complexidade das situações, a questão central é aonde se pode chegar realisticamente com determinadas intervenções. Obviamente, não seria possível transformar uma situação sócio-econômica precária, existente durante décadas ou séculos, numa situação completamente diferente no decorrer de poucos anos e em função de alguns projetos com apoio internacional.

Partindo dessa suposição, é fundamental reconhecer a necessidade de decisões estratégicas sobre a aplicação dos escassos recursos, que inclui a definição do que se pretende realizar e aonde se pretende chegar. Assim, podem ser evitadas frustrações e decepções nos dois lados: no lado dos que apóiam o empreendimento e que precisam prestar conta dos seus investimentos frente ao público que arca com os custos; e no lado dos que recebem o apoio, que podem evitar expectativas excessivas e irrealistas. É claro que também não será apenas o QL que pode dar todas as respostas, mas ele pode ajudar significativamente na definição de um consenso sobre o projeto.

$\mathrm{O}$ QL consiste de um conjunto de conceitos interdependentes que descrevem de um modo operacional e organizado numa matriz os aspectos mais importantes de um projeto de intervenção. Essa descrição permite, 
em primeiro lugar, verificar se um projeto está bem-estruturado e, em segundo lugar, o acompanhamento sistemático e uma avaliação mais fácil e mais objetiva.

\section{Figura 1: Estrutura do Quadro Lógico}

\begin{tabular}{|l|l|l|l|l|}
\cline { 2 - 5 } \multicolumn{1}{c|}{} & $\begin{array}{l}\text { Lógica da } \\
\text { Intervenção }\end{array}$ & $\begin{array}{l}\text { Indicadores } \\
\text { Objetivamente } \\
\text { Comprováveis }\end{array}$ & $\begin{array}{l}\text { Fontes de } \\
\text { Comprovação }\end{array}$ & $\begin{array}{l}\text { Suposições } \\
\text { Importantes }\end{array}$ \\
\hline $\begin{array}{l}\text { Objetivo } \\
\text { Superior }\end{array}$ & & & & \\
\hline $\begin{array}{l}\text { Objetivo } \\
\text { do Projeto }\end{array}$ & & & & \\
\hline Resultados & & & & \\
\hline $\begin{array}{l}\text { Atividades } \\
\text { Principais }\end{array}$ & & & & \\
\hline
\end{tabular}

Trata-se de uma apresentação estruturada do conteúdo de um projeto de intervenção, na qual existe uma relação causal entre níveis: atividades/resultados, resultados/objetivo do projeto e objetivo do projeto/ objetivo superior. Essa cadeia e suas relações devem ser lógicas e plausíveis, mas não se trata de uma simples relação de causa/efeito. Levando em consideração que um projeto de desenvolvimento necessariamente encontra barreiras e limitações, também precisa ser incluído nessa lógica o elemento suposições importantes, que são fatores externos ao projeto, mas necessários para o seu êxito.

Uma outra relação lógica considerada é aquela que vincula cada resultado e objetivo a um indicador que, por sua vez, está vinculado a uma fonte de comprovação.

Falar de lógica é inevitável quando se trata de uma metodologia que se chama QL. Mas, na prática, pode-se verificar que, ao contrário do que isto sugere, lógica não significa necessariamente coerência de raciocínio ou de idéias de uma forma universal. Por exemplo, encontram-se dois conceitos na literatura sobre o QL que são interpretados de maneiras diferentes: a lógica vertical e a lógica horizontal.

A lógica vertical diz respeito à primeira coluna, a Lógica da Intervenção, segundo a qual, insumos e trabalho (Atividades) aplicados produzem resultados, estes provocam um efeito (Objetivo do Projeto), que por sua vez contribui para um Objetivo Superior. A Lewis Grant Associates (s/d), por exemplo, define este raciocínio como a lógica vertical. 
Mas o raciocínio da GTZ (Bolay, 1993:59) é que esta relação será incompleta se não forem levadas em consideração as Suposições Importantes, que complementam a cadeia lógica, pois são consideradas essenciais. Por isso, a ascensão de um nível (de Resultados, por exemplo) para o próximo nível superior (Objetivo do Projeto), seria possível apenas com a inclusão das suposições. Daí, a lógica vertical consistiria de: Resultados alcançados mais Suposições no mesmo nível (de Resultados) levam ao nível imediatamente superior (Objetivo do Projeto).

O outro conceito é a lógica horizontal. Conforme Bolay (op.cit.), esta seria composta pelo Resultado (ou Objetivo do Projeto, ou Objetivo Superior) mais seus respectivos Indicadores Objetivamente Comprováveis, mais suas respectivas Fontes de Comprovação, todos encontrando-se no mesmo nível do quadro e, portanto, numa linha horizontal.

Já a Lewis Grant Associates ( $\mathrm{s} / \mathrm{d}$ ) raciocina que, além dos indicadores e das fontes, as suposições também se encontram no mesmo nível e, portanto, estes últimos fariam parte da lógica horizontal.

O exemplo mostra como é difícil alcançar uma definição conceitual sobre lógica, mesmo antes de se discutir os conteúdos. Por outro lado, neste caso, as diferenças conceituais não têm maiores implicações práticas. Ambas as explicações têm razão e ambas poderiam chegar ao mesmo preenchimento do QL.

Com o fim de posicionamento, defendemos aqui o raciocínio de Bolay, por considerar a Lógica de Intervenção apenas plausível quando forem consideradas adequadamente as suposições.

\section{Descrição do Quadro Lógico}

As preocupações para quem utiliza o QL são a transparência e a precisão. Tendo em vista a complexidade da comunicação humana, o método sugere a aplicação de uma linguagem que contribua para a redução de interpretações e mal-entendidos.

Em propostas prolixas de projetos é freqüente que o leitor tenha muito espaço para interpretações sobre o conteúdo. Uma das práticas mais comuns é a descrição daquilo que se pretende fazer no projeto, denominando isso objetivos. Não é raro encontrar-se projetos com vários objetivos gerais e ainda uma série de objetivos específicos, todos formulados como atividades ou processos. Dois problemas derivam desta prática: primeiro, com diversos objetivos estabelecidos, o projeto corre o risco de ficar sem foco claro; segundo, a descrição das atividades ou processos muitas vezes não deixa claro aonde se pretende chegar. Pressupõe-se apenas que fazer o que se planeja levará a efeitos positivos. 
Em busca de maior precisão desde o planejamento de um projeto, o

QL propõe a descrição dos objetivos e resultados de tal forma que se consiga visualizar o alcançado. Para isso, é usado o verbo no particípio para os resultados, assim como se o estado já fosse alcançado, enquanto as atividades são descritas com um verbo no infinitivo (ver exemplo em anexo 2).

Da mesma forma, utiliza-se na descrição do objetivo do projeto e do objetivo superior, o presente, descrevendo a situação futura desejada. Quando essa visão é descrita fica mais claro aonde se quer chegar do que quando se descreve apenas o que se pretende fazer.

$\mathrm{O}$ uso dessa linguagem parece geralmente um pouco estranho à primeira vista, mas as pessoas logo se acostumam porque percebem que ela é mais precisa. Esse recurso ajuda, na prática, a reduzir o grau de incertezas e dúvidas. Ao mesmo tempo, ele contribui para provocar a transparência de conflitos ou incompatibilidades, se houver, porque a lógica exigida permite muito menos compromissos. Por outro lado, se esses conflitos forem resolvidos num estágio inicial, as chances de êxito do projeto são certamente maiores.

\subsection{Primeira coluna: Lógica da Intervenção}

\section{Objetivo Superior}

Este objetivo é principalmente um objetivo de orientação. Ele é necessário porque orienta de forma geral a atuação do projeto dentro do contexto organizacional. Ele está geralmente ligado à missão da organização responsável pelo projeto ou à missão da organização financiadora. O Objetivo Superior, em inglês chamado goal, é relativamente amplo e tem o caráter de uma visão do futuro, mas ele tem que ser visível, palpável, realisticamente alcançável: ele não deve estar longe demais. Isto é importante para poder ajudar a motivar as pessoas envolvidas.

Quando o QL é combinado com métodos de planejamento estratégico, o Objetivo Superior poderia ser um objetivo estratégico e vários projetos poderiam ter o mesmo Objetivo Superior. O mesmo ocorre dentro de um programa.

A relação com o Objetivo do Projeto é que este último deve contribuir para o Objetivo Superior. Esta contribuição deve ser de forma significativa e mensurável, para evitar que ele seja muito amplo e genérico, sem a função específica de orientação. Como se trata de uma contribuição apenas, é possível que um projeto tenha mais de um Objetivo Superior. 


\section{Objetivo do Projeto}

Em inglês, este objetivo é chamado purpose ou outcome, porque ele visa explicitar qual é o propósito da intervenção. Em lugar de descrever o que se pretende fazer, aqui é descrita aquela nova situação que se visa alcançar com a realização do projeto. Essa nova situação seria, na verdade, o efeito esperado da intervenção e, portanto, deve considerar também as mudanças de comportamento na atuação das pessoas que desejam melhorar a sua atual situação.

A razão para esta definição de objetivo é a visão do que é um problema. Parte-se da suposição de que todo projeto de desenvolvimento tem como ponto de partida problemas que, no seu conjunto, formam uma situação-problema. Esses problemas estão sempre ligados a pessoas que, por um lado, são afetadas por eles, mas que por outro lado, muitas vezes são também causadoras deles, pelo menos parcialmente.

Se um problema é definido como um estado negativo existente, percebido por pessoas, um objetivo pode ser definido como um estado positivo desejável. Mas quando as causas dos problemas são amplamente analisadas, descobre-se geralmente que os afetados por eles precisam fazer parte das soluções. Enquanto isso pode até parecer óbvio, na prática, não é fácil, porque muitas vezes soluções sustentáveis são alcançadas apenas com uma mudança de hábitos e comportamentos. Não são apenas obras de infra-estrutura, por exemplo, que melhoram as condições de vida, mas a infra-estrutura precisa ser adequadamente usada, e isso pode implicar na necessidade de mudar hábitos.

Daí resulta a preocupação do enfoque QL com o Objetivo do Projeto. Ele deve expressar aquelas mudanças que serão provocadas no grupoobjetivo pelos resultados do projeto. Pressupõe-se que, sem essa mudança, as melhorias que um projeto pode prover não teriam sustentabilidade, ou seja, não haveria desenvolvimento, entendido como um processo de transformação e melhoria ao longo do tempo.

Essa preocupação resultou exatamente das experiências que diversas organizações bilaterais e internacionais fizeram nas primeiras duas décadas da cooperação em desenvolvimento. Os investimentos feitos muitas vezes não conseguiram contribuir muito para o desenvolvimento num sentido mais amplo, mesmo quando os projetos eram tecnicamente bem feitos, porque não foram acompanhados por uma mudança de comportamento. Se as pessoas envolvidas num processo para solucionar a situação-problema continuam agindo como sempre agiram, a introdução de novas tecnologias não poderá trazer os efeitos desejados. O mesmo ocorre em projetos de desenvolvimento organizacional. 
Além da preocupação com as mudanças nos grupos-alvo, o enfoque QL tem uma preocupação com a eficiência. Para evitar um problema muito frequiente de projetos complexos, o método exige que se defina apenas um Objetivo do Projeto. Isso obriga os envolvidos no planejamento a discutir as diversas alternativas possíveis e selecionar um enfoque ${ }^{7}$. Com isso, o projeto ganha um rumo claro e facilita a organização de todo o processo de implementação.

Por outro lado, definir o Objetivo do Projeto com aqueles efeitos que são desejáveis, mas que dependem, em última instância, do próprio grupo-alvo, significa que a gerenciabilidade deste objetivo é limitada.

Podem ser distintos também dois tipos de efeitos: efeitos diretos, ou seja, aqueles que se espera diretamente em função do projeto e que se expressam em nível do Objetivo do Projeto; e os efeitos indiretos, que são aqueles que se almeja a longo prazo e que dependem de uma série de outras influências, além do projeto. Esses se encontram em nível do Objetivo Superior.

\section{Resultados}

Resultados são aqueles bens ou serviços produzidos pelo projeto, isto é, pela organização responsável pelo projeto e pelas organizações ou grupos que participaram efetivamente da sua implementação. Os resultados descrevem o escopo do projeto, ou seja, descrevem aquilo que é gerenciável pelo projeto e o que é da responsabilidade de sua gerência. Assim, o QL faz uma distinção clara entre conceitos que são freqüentemente confundidos: objetivo e resultado ${ }^{8}$.

A distinção desses conceitos não é apenas uma questão semântica, as implicações para o gerenciamento de projeto são fundamentais. Enquanto o Objetivo do Projeto é um efeito desejado, mas que foge do controle e da responsabilidade direta da gerência do projeto, o alcance dos Resultados tem que ser gerenciado de tal forma que pode ser atribuído aos esforços do projeto. Um outro termo usado em inglês para Resultado é output (saída), o que indica o final de um processo de produção, respectivamente de transformação.

A relação entre os dois níveis é a de plausibilidade, ou seja, o alcance do Objetivo do Projeto tem que estar baseado em resultados suficientes e necessários e em Suposições Importantes cujo risco de não ocorrerem não deve ser demasiado grande. Obviamente, nesse ponto não é o método que dá a resposta, senão os planejadores que avaliam essa probabilidade.

Já a relação entre os Resultados e o nível inferior, as Atividades Principais, tem que ser uma relação lógica. Isto é, o planejamento tem que prever atividades suficientes para poder produzir os bens ou serviços necessários para o alcance do Objetivo do Projeto. Assim, a definição 
dos Resultados tem que acontecer de tal maneira que a gerência do projeto possa assumir a responsabilidade sobre os alcances.

\section{Atividades Principais}

Para produzir os desejados bens e serviços, determinadas atividades precisam ser realizadas. Para cada Resultado, uma série de Atividades Principais é elaborada. A relação entre o nível destas e o nível dos Resultados é também uma relação lógica: devem existir atividades suficientes e necessárias a fim de alcançar os Resultados e, portanto, o planejamento dessas é também responsabilidade da gerência do projeto. Se as atividades previstas não forem suficientes, os resultados não poderão ser alcançados e, se não forem necessárias, significa que o projeto desperdiça recursos. Assim, a definição delas ajuda a definir claramente o escopo do projeto, porque são elas que permitem estimar os recursos necessários.

Cabe ainda mencionar um aspecto que diz respeito à clareza que o QL procura pelo uso da linguagem. Se um objetivo é entendido e definido como uma situação futura desejada, ele é descrito no QL como se já estivesse alcançado. Igualmente são descritos os resultados como se tivessem obtido esses produtos ou serviços. Já as atividades são descritas com um verbo no infinitivo. Desta forma, é mais fácil para o leitor da proposta do projeto entender aonde se pretende chegar e o que é preciso fazer".

\section{Insumos/Recursos}

A última relação na Lógica da Intervenção é aquela entre as atividades e os recursos necessários. O QL original e a maioria dos formatos não inclui os insumos ${ }^{10}$. Do ponto de vista da lógica, este nível poderia ser incluído no QL, já que é fundamental considerar os recursos. Por outro lado, a matriz talvez ficasse sobrecarregada de informações, que poderiam ser fornecidas em outro lugar. De todo modo, a relação Insumos/Atividades precisa ser estabelecida de forma lógica e realista. É obvio que a insuficiência de Recursos não permitiria realizar todas as Atividades previstas e, conseqüentemente, comprometeria um ou mais dos Resultados. Com isso, o Objetivo do Projeto não poderia ser alcançado, nem a contribuição para o Objetivo Superior.

A parte inferior da Lógica de Intervenção está, portanto, baseada na lógica de um processo de produção:

\section{Figura 2: Processos de produção}

\begin{tabular}{|c|c|c|c|c|}
\hline $\begin{array}{l}\text { Processo genérico } \\
\text { de produção }\end{array}$ & $\begin{array}{l}\text { insumos } \\
\text { (ou entradas) }\end{array}$ & $\Rightarrow$ transformação & $\Rightarrow$ & produto \\
\hline $\begin{array}{l}\text { Processo da produção } \\
\text { de Resultados }\end{array}$ & insumos & $\Rightarrow$ atividades & $\Rightarrow$ & resultados \\
\hline
\end{tabular}


Vários resultados esperados de um projeto exigem vários processos que, a rigor, podem ser subdivididos em outros subprocessos. $\mathrm{O}$ desafio que o QL enfrenta é a seleção e combinação adequada daqueles processos que são capazes de produzir os efeitos desejados de uma maneira eficiente.

Quando estabelecida, a consistência da Lógica de Intervenção pode ser averiguada com uma "dupla checagem” perguntando do nível de baixo para cima o porquê da relação e, descendo, perguntando como chegar ao nível de baixo.

\section{Figura 3: Cadeia lógica de objetivos}

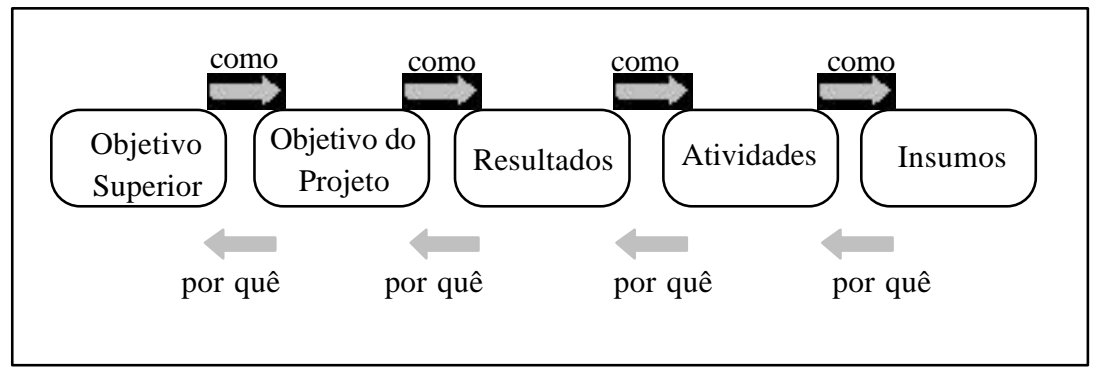

Gráfico adaptado de: Baccarini (1999) e Boiteux (1984)

Um dos aspectos mais importante do QL é a diferenciação entre o escopo gerenciável (até os Resultados) e o escopo não-gerenciável, mas considerado como contexto e referência (Objetivo do Projeto e Objetivo Superior). À primeira vista pode parecer paradoxal definir um Objetivo do Projeto que não é completamente gerenciável. A explicação é que o êxito de um projeto pode ser definido em, no mínimo, dois níveis ou, como Baccarini (1999:25) argumenta, existem dois conceitos de êxito de um projeto:

"Êxito do gerenciamento do projeto project management success) que enfoca no processo do projeto e, em particular, na exitosa conclusão das metas de custo, tempo e qualidade. Este aspecto também considera a maneira como o processo de gerenciamento foi conduzido.

Êxito do produto (product success). Este trata dos efeitos do produto final do projeto."

Baccarini (op.cit.) ainda alerta que é comum na literatura especializada em gerenciamento de projeto que esses dois componentes diferentes sejam confundidos, como se fossem um único grupo.

É o QL que combina esses dois componentes em um quadro, mas os visualiza e separa conceitualmente. $\mathrm{O}$ fato de Baccarini usar o termo 
produto está relacionado ao contexto de empresas privadas. Mas o conceito básico do Objetivo do Projeto purpose é o mesmo, quando diz que a realização exitosa do purpose pode ser mensurada em termos de quão bem o produto do projeto satisfaz as necessidades do usuário.

Este raciocínio pode ser representado da seguinte forma:

\section{Figura 4: Eficiência e}

\section{efetividade no Quadro Lógico}

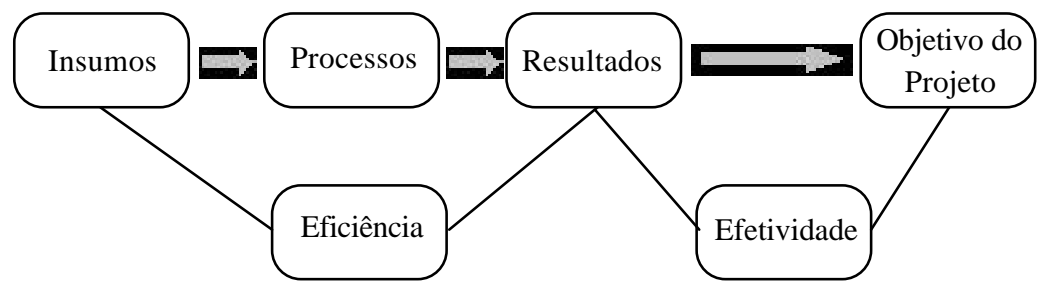

Gráfico adaptado de: Intervention (s/d:5)

Traduzido para o contexto de projetos de desenvolvimento, isto significa que não é suficiente gerenciar bem o processo da construção de um hospital, por exemplo, se este não consegue contribuir para a melhoria do estado de saúde. $\mathrm{Ou}$, se um projeto de infra-estrutura bem gerenciado não consegue alavancar o desenvolvimento econômico, o seu êxito é limitado porque não há efetividade da intervenção.

\subsection{Segunda coluna: Indicadores Objetivamente Comprováveis}

A busca de eficácia, eficiência e bom desempenho leva à questão da mensurabilidade desses aspectos, o que foi o ponto de partida para a elaboração do QL. Essa preocupação é considerada na segunda coluna da matriz com os Indicadores Objetivamente Comprováveis.

Um indicador é uma situação ou caraterística que serve como sinal comprobatório de um outro fato. Trata-se, no caso do QL, de uma descrição operacional dos objetivos e dos resultados em termos de quantidade e qualidade de um produto ou serviço para o grupo-objetivo, indicando ainda o tempo (ou prazo) e o local (ou espaço). O termo objetivamente diz respeito à necessidade de especificar os indicadores de tal forma que sua mensuração seja independente de "achismos" ou de opiniões pessoais, senão baseadas em fatos e evidências. Idealmente, os indicadores tratam dos seguintes aspectos:

- o grupo-objetivo quem é beneficiado?

- a quantidade quanto? 
- a qualidade

- o período

- a localização quão bem?

quando e quanto tempo?

onde?

As funções dos indicadores são: caracterizar mais detalhadamente os objetivos e resultados, estabelecendo o que e quanto se pretende alcançar, e fornecer uma base para o acompanhamento e a avaliação do planejado.

Devido ao fato de que os níveis do QL têm caraterísticas e funções diferentes, os indicadores que dizem respeito a esses níveis também se diferenciam. Os Resultados, que são os produtos pelos quais a gerência do projeto se responsabiliza, exigem indicadores de acompanhamento ${ }^{11}$. Eles descrevem esses produtos em termos do que terá sido feito, o quanto dele, quando e quão bem. Esses indicadores dos outputs têm que estar consistentes com os inputs, ou seja, com os recursos e o trabalho aplicado (Atividades).

Por outro lado, o Objetivo do Projeto e o Objetivo Superior expressam efeitos esperados e, portanto, os seus indicadores são indicadores de efeito. Conforme as caraterísticas dos dois objetivos, os indicadores podem ser diferenciados como indicadores de efeitos diretos para o Objetivo do Projeto e indicadores de efeitos indiretos para o Objetivo Superior. Em todo caso, eles devem mensurar aquelas mudanças que se espera ocorrer nas pessoas e nas organizações envolvidas, em função da atuação do projeto. De modo geral, não existem unidades métricas já definidas para medir em metros ou pesar em toneladas as mudanças. Portanto, indicadores de efeito são quase sempre indicadores indiretos e muitas vezes é necessário um conjunto de indicadores que mostre as diferenças da situação antes do projeto.

O Banco Mundial (1996:4) definiu os seguintes tipos de indicadores:

\section{Figura 5: Tipos de objetivos e indicadores}

\begin{tabular}{l|l}
\hline Nível de objetivo & Tipo de indicador \\
\hline Objetivo Superior (Goal) & Impacto \\
\hline Objetivo do Projeto (Purpose) & Outcome ou Efeito \\
\hline Resultados (Outputs) & Output \\
\hline Atividades (Activities) & Processo \\
\hline Insumos (Inputs) & Input \\
\hline
\end{tabular}

Os indicadores fazem parte de praticamente todas as variações do $\mathrm{QL}^{12}$ e, na prática, é sempre um dos aspectos mais discutidos, porque 
neles se reflete o grau das melhorias que se pode esperar e, ao mesmo tempo, representam um compromisso por escrito por parte da organização executora. Para a gerência do projeto, é extremamente importante prestar atenção a este aspecto porque é uma referência muito importante para a avaliação do projeto.

A busca de indicadores adequados pode desencadear também um novo processo de discussão sobre os objetivos ou resultados definidos previamente, porque consensos alcançados na definição dos objetivos podem revelar-se como fracos e insustentáveis.

\subsection{Terceira coluna: Fontes de Comprovação}

A definição de indicadores apropriados é um processo bastante difícil e complexo e não pode sempre ser concluído num grupo de participantes muito grande. Mas existe ainda uma outra dificuldade: indicadores úteis não são aqueles que medem apenas teoricamente os resultados ou os objetivos. Para evitar que sejam definidos indicadores cujas informações não podem ser averiguadas na prática, o QL contém a terceira coluna com as Fontes de Comprovação ${ }^{13}$. A Fonte de Comprovação indica onde se encontram as informações e os dados dos indicadores. Nela são registradas aquelas fontes ou meios (locais e documentos) que poderão ser utilizadas para verificar o conteúdo dos indicadores. Fontes podem ser estatísticas oficiais, pesquisas de opinião pública ou outras publicações para os indicadores de efeito, e são geralmente documentos produzidos pelo próprio sistema de informações gerenciais dos projetos para os resultados.

Assim, as Fontes de Comprovação têm várias funções: primeiro, a sua definição obriga a definir indicadores realistas, porque se não forem encontradas fontes adequadas para verificar a informação contida no indicador, o indicador não serve; segundo, se não houver fontes adequadas, mas se quer manter o indicador, a definição das fontes mostrará em que custos adicionais isto poderá implicar; terceiro, as fontes definidas mostram alguns dos elementos necessários para o estabelecimento de um sistema de informações gerenciais do projeto.

Em todo caso, é fundamental que fontes adequadas existam e que elas sejam confiáveis. É possível para o próprio projeto construir fontes, mas neste caso sempre devem ser considerados o custo e a viabilidade. Se não houver fontes adequadas para mensurar um determinado indicador, ele simplesmente não serve.

A maioria das fontes para os indicadores de acompanhamento são estabelecidas e mantidas pelo próprio projeto, já que fazem parte do sistema de informações gerenciais. No entanto, as fontes para os indicadores de efeito devem ser externas também. 
Para a avaliação de um projeto, intermediária ou final, as Fontes de Comprovação são referências fundamentais.

\subsection{Quarta coluna: Suposições Importantes}

Projetos que visam produzir mudanças em pessoas ou organizações encontram necessariamente uma série de barreiras e riscos que dificilmente podem ser detectados na sua totalidade no início do processo. Mesmo com a viabilidade analisada e confirmada, podem ocorrer mudanças desfavoráveis, capazes de comprometer o êxito do projeto. Um bom planejamento pode reduzir consideravelmente possíveis riscos pelo esclarecimento e solução das condições prévias, mas certamente permanecerão alguns fatores importantes para o êxito do projeto que estão fora do controle da gerência. Esses fatores são chamados Suposições Importantes $^{14}$ e são considerados no QL na quarta coluna.

Suposições são fatores que, para fins de planejamento, são considerados verdadeiros, reais ou certos. No caso do QL trata-se de fatores externos que escapam à influência direta da gerência do projeto, mas que são importantes para o êxito da intervenção. Suposições representam geralmente um certo risco e, portanto, devem ser avaliadas cuidadosamente para não comprometerem o êxito do projeto, e o seu comportamento deve ser monitorado ao longo do tempo.

Suposições podem estar ligadas ao grupo-alvo do projeto. Por exemplo, um projeto que visa alcançar mudanças por meio de educação tem que supor que as pessoas assimilem o aprendizado e de fato o apliquem depois. Por melhor que seja preparada e realizada a capacitação, a efetiva assimilação e aplicação estão fora do controle da gerência. No entanto, se elas não ocorrerem, o projeto não terá êxito, mesmo se ele for bem gerenciado $^{15}$. Suposições podem estar ligadas também a fatores políticos ou macroeconômicos, que podem estar favoráveis hoje, mas desfavoráveis no futuro.

A inclusão de uma Suposição Importante depende da sua avaliação. Em primeiro lugar, ela tem que ser importante para o êxito do projeto. Segundo, tem que existir um certo grau de risco de ela não ocorrer. E, terceiro, se for identificado que ela é importante, mas que é pouco provável que ocorra, significa que o êxito do projeto está em jogo e, conseqüentemente, a estratégia da intervenção deve ser mudada.

A suposição faz parte da lógica vertical, pois o alcance de um resultado, por exemplo, mais a afirmação da Suposição ao mesmo nível, leva ao nível imediatamente superior, que é o Objetivo do Projeto. Este alcançado, mais a Suposição ao mesmo nível leva ao Objetivo Superior.

Uma Suposição Importante em nível do Objetivo Superior nem sempre é encontrada. Há divergências quanto à necessidade ou à utilidade 
deste campo do Quadro Lógico. Como a Suposição Importante sempre deve ser vista em conjunto com a ascensão ao nível superior, não tendo mais nível superior, ela não faria sentido. Por outro lado, existe a posição de que este campo deve ser preenchido por uma suposição que ajude a garantir a sustentabilidade do Objetivo Superior alcançado.

A elaboração das Suposições Importantes é uma espécie de análise de risco, mas limitada a riscos externos. Riscos internos ao projeto ou à organização executora do projeto não são considerados no QL. Para isso, devem ser realizadas análises de risco específicas.

Realizando uma "chuva" de idéias, uma equipe de planejamento pode coletar rapidamente um grande número de fatores externos que são importantes para o projeto. Mas não é no sentido do QL incluir o maior número possível. Para evitar isso é realizada uma avaliação, utilizando o esquema a seguir:

\section{Figura 6: Esquema para a}

\section{apreciação dos fatores externos}

$1^{\text {a }}$ Pergunta: A suposição é importante?

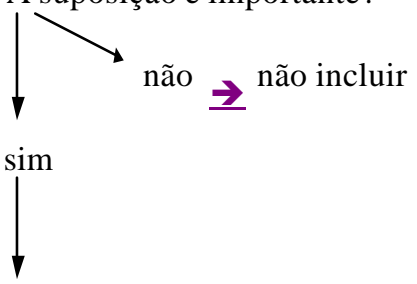

$2^{\text {a }}$ Pergunta: Quão provável é que ocorra?

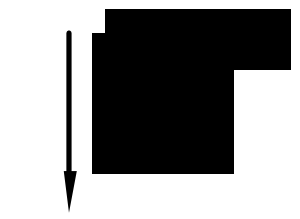

improvável

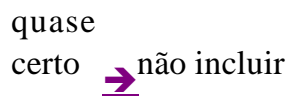

quase

certo $\rightarrow$ não incluir

certa

probabilidade incluir no Quadro Lógico.

A gerência do projeto tem de:

- monitorar

- tentar influenciar

$3^{\text {a }}$ Pergunta: É possível mudar a estratégia do projeto, de modo a não precisarmos dessa suposição?

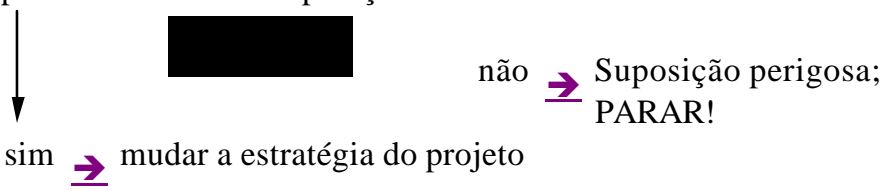


Além da sua importância ou relevância, é avaliada também a probabilidade da sua ocorrência. Se um fator é considerado importante mas altamente provável que ocorra, ele não é incluído no QL.

Apenas se um fator tem uma certa probalidade de ocorrer, mas também existe um certo risco de não ocorrer, este fator é incluído no QL e formulado de tal maneira que ele pode ser afirmado. Essa forma é necessária para possibilitar a leitura Resultado + Suposição leva ao Objetivo, por exemplo. Essa dupla negação (negar um fato negativo) exige, às vezes, bastante orientação por parte do moderador, mas é parte da estrutura lógica do quadro.

Se um fator externo é considerado importante, mas ao mesmo tempo improvável que ocorra, significa que: ou há uma quebra lógica na estrutura do projeto ou então há um fator que impede o projeto de ter êxito. Isso significa que: ou o projeto não deve ser realizado ou a sua estratégia deve ser mudada de tal maneira que esse fator não possa mais impedir o êxito.

Se esse exercício for levado até as últimas conseqüências, muitos projetos não deveriam ser começados, porque com freqüência são revelados empecilhos tão grandes que o êxito dependeria de muita sorte. Mas, apesar do QL ser aplicado em praticamente todos os projetos de cooperação internacional, Suposições Importantes são ignoradas ou reinterpretadas ou reformuladas de tal maneira que não evidenciam mais o grau de risco.

Uma das conclusões mais significativas da análise da estrutura do QL é que ele ajuda a visualizar os componentes gerenciáveis de um projeto e seu contexto com seus limites e riscos. Com isso, ele representa uma valiosa ferramenta para a análise estratégica de intervenções.

\section{Figura 7: Gerenciabilidade de um projeto}

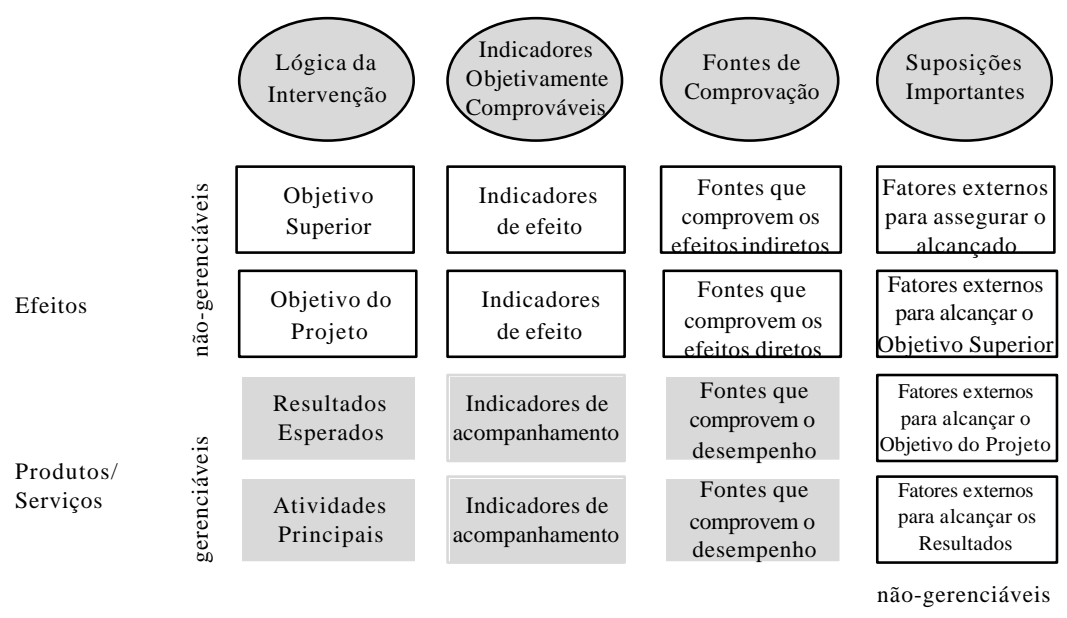




\section{Exemplo Demonstrativo}

A fim de ilustrar a aplicação prática dos conceitos do QL, apresentamos a seguir um exemplo demonstrativo. Para tratar cada elemento individualmente, o QL é desagregado. O seu conjunto encontra-se no anexo 2.

O exemplo demonstrativo é um projeto de desenvolvimento típico, no qual o Ministério de Agricultura de um país sem muitos recursos busca alavancar a produção agrícola de uma região selecionada por meio de um projeto. As análises da situação, incluindo problemas, atores, potenciais, objetivos e alternativas já foram realizadas.

\subsection{Primeira coluna: Lógica da Intervenção}

\begin{tabular}{l|l}
\hline Definição & Lógica da Intervenção \\
\hline $\begin{array}{l}\text { É o objetivo ao qual o projeto pretende } \\
\text { contribuir. A contribuição deve ser signifi- } \\
\text { cativa (mensurável). É possível que ele } \\
\text { seja alcançado somente algum tempo } \\
\text { depois da conclusão do projeto. }\end{array}$ & $\begin{array}{l}\text { Objetivo Superior } \\
\text { Situação sócio-econômica da } \\
\text { região melhorada. }\end{array}$ \\
\hline $\begin{array}{l}\text { É o propósito do projeto. Ele descreve } \\
\text { a situação futura desejada e realistica- } \\
\text { mente alcançável. É o foco da interven- } \\
\text { ção e, portanto, deve existir apenas } \\
\text { um Objetivo do Projeto. Idealmente, } \\
\text { ele mostra as mudanças desejadas. }\end{array}$ & $\begin{array}{l}\text { Objetivo do Projeto } \\
\text { na produção de arroz. }\end{array}$ \\
\hline $\begin{array}{l}\text { São bens ou serviços produzidos pelo } \\
\text { projeto, e apenas pelo projeto. Estes } \\
\text { produtos têm que ser gerenciáveis e } \\
\text { alcançáveis com os recursos disponíveis. }\end{array}$ & $\begin{array}{l}\text { Resultados } \\
\text { Os resultados são aquilo que é “entre- } \\
\text { gue” pelo projeto (deliverables). }\end{array}$ \\
$\begin{array}{l}\text { 2. Serviçonando de Assistência Agrícola } \\
\text { está fortalecido. }\end{array}$ \\
$\begin{array}{l}\text { 3. Financiamento para mecanização } \\
\text { é facilitado. }\end{array}$ \\
$\begin{array}{l}\text { 4. Sistema de comercialização } \\
\text { implantado e funcionando. }\end{array}$ \\
\end{tabular}

Um suposto projeto de desenvolvimento de uma região agrícola escolheu o foco da produção mais promissora. Os Resultados são, a princípio, gerenciáveis, desde que disponha dos recursos materiais e humanos necessários. Já o Objetivo do Projeto foge ao controle direto da gerência, porque supõe uma mudança na maneira de atuar dos agricultores. Mesmo eles sendo treinados e apoiados, existe um fator de risco que indica que a 
mudança necessária possa não ocorrer. Por outro lado, formulando o Objetivo do Projeto desta forma, mostra também aos próprios agricultores que a mudança desejada para a região depende da mudança de hábitos deles.

Pressupondo a existência dos recursos necessários e uma eficiente aplicação deles nas atividades é possível produzir os cinco Resultados. No entanto, sempre deve-se verificar se realmente todos os Resultados são necessários para alcançar o Objetivo do Projeto, porque se não, haveria desperdício de recursos. Por outro lado, tem que ser verificado também se os cinco Resultados são suficientes para alavancar o Objetivo do Projeto, pelo menos do ponto de vista dos fatores gerenciáveis.

Desta forma, é realizada uma definição do escopo do projeto, porque nos resultados estão incluídos todos aqueles principais produtos e serviços que o projeto pretende entregar até o final do seu ciclo de vida.

No exemplo apresentado acima, esta relação é lógica e plausível e, a princípio, gerenciável. A soma dos cinco Resultados e o efeito da sua interação podem levar ao Objetivo do Projeto, desde que seja levada em consideração a atitude dos próprios agricultores, bem como outros fatores externos ao controle gerencial.

O Quadro Lógico também evidencia as áreas de responsabilidade direta do gerenciamento do projeto e os aspectos que não são diretamente controláveis. As relações Insumos/Atividades e Atividades/Resultados são da responsabilidade direta da gerência. Se os Resultados não são alcançáveis por falta de recursos, por exemplo, as Atividades devem ser adaptadas aos recursos disponíveis e, eventualmente, os Resultados devem ser reformulados. Ou, se um Resultado depende de atividades de terceiros, ele deve somente ser incluído se a responsabilidade está claramente definida. Desta forma, os Resultados (bens ou serviços produzidos pelo projeto) são gerenciáveis.

Já o Objetivo do Projeto escapa do controle direto, porque se trata de um efeito esperado em função das inter-relações entre os Resultados, além de depender de fatores externos (Suposições). Portanto, o Objetivo do Projeto "Agricultores aplicam novas técnicas na produção de arroz" não é completamente gerenciável.

Igualmente, o alcance do Objetivo Superior não pode ser controlado pelo gerenciamento, tanto porque o Objetivo do Projeto apenas contribui para o seu alcance quanto pelo fato de que este depende também de outras intervenções ou ações. 
4.2. Quarta coluna: Suposições Importantes

\begin{tabular}{|c|c|c|c|}
\hline Lógica da Intervenção & $\begin{array}{l}\text { Indicadores } \\
\text { Objetivamente } \\
\text { Comprováveis }\end{array}$ & $\begin{array}{l}\text { Fontes de } \\
\text { Comprovação }\end{array}$ & $\begin{array}{l}\text { Suposições } \\
\text { Importantes }\end{array}$ \\
\hline $\begin{array}{l}\text { Objetivo Superior: } \\
\text { Situação sócio-econômi- } \\
\text { ca da região melhorada. }\end{array}$ & & & $\begin{array}{l}\text { Política de desenvol- } \\
\text { vimento prioriza a } \\
\text { produção de arroz. }\end{array}$ \\
\hline $\begin{array}{l}\text { Objetivo do Projeto: } \\
\text { Agricultores aplicam } \\
\text { novas técnicas na pro- } \\
\text { dução de arroz. }\end{array}$ & & & $\begin{array}{l}\text { • Não há migração } \\
\text { para a região do } \\
\text { projeto. }\end{array}$ \\
\hline $\begin{array}{l}\text { Resultados: } \\
\text { 1. Sistema de irrigação } \\
\text { implantado e funcio- } \\
\text { nando. } \\
\text { 2. Serviço de Assistên- } \\
\text { cia Agrícola está } \\
\text { fortalecido. } \\
\text { 3. Financiamento } \\
\text { para mecanização é } \\
\text { facilitado. } \\
\text { 4. Sistema de } \\
\text { comercialização } \\
\text { implantado e } \\
\text { funcionando. } \\
\text { 5. Agricultores } \\
\text { capacitados. }\end{array}$ & & & $\begin{array}{l}\text { • Não há desastres } \\
\text { naturais. } \\
\text { • Não há disputas } \\
\text { excessivas pelo uso } \\
\text { d'água. } \\
\text { • Não há evasão } \\
\text { de assessores } \\
\text { capacitados. } \\
\text { - Preço do combustí- } \\
\text { vel não aumenta mais } \\
\text { que 5\%. } \\
\text { - O preço internacio- } \\
\text { nal do arroz não } \\
\text { baixa mais que 10\%. } \\
\text { - Agricultores } \\
\text { assimilam o novo } \\
\text { conhecimento. }\end{array}$ \\
\hline
\end{tabular}

A coluna da Lógica da Intervenção poderia ser, teoricamente, elaborada de forma coerente, lógica, consistente e plausível, se o projeto não precisasse preocupar-se com o seu ambiente. No entanto, nenhum projeto atua num vácuo e, portanto, tem que relacionar-se com o seu entorno. Isso pode afetar fundamentalmente a Lógica da Intervenção.

Especialmente projetos de desenvolvimento que, por natureza, têm que enfrentar situações desfavoráveis com relação a estruturas existentes, são freqüentemente confrontados com barreiras ou limitações que são difíceis para gerenciar. Por outro lado, um projeto que não encontraria nenhuma resistência ou nenhuma barreira dificilmente afetaria estruturas existentes. O QL leva esse fato especialmente em consideração com a inclusão de Suposições Importantes. O exemplo acima demonstra a relação e a relevância deste elemento no QL. 
Os Resultados devem ser, por definição, gerenciáveis, apesar do fato de também existirem riscos de não alcançá-los. Por exemplo, quando do planejamento, pressupõe-se que haverá uma equipe competente à disposição. Essa equipe poderia ser contratada e ser gerenciada pela gerência do projeto. No entanto, não se sabe ao certo se as pessoas escolhidas teriam o desempenho esperado. Além disso, ao longo do tempo, poderão ocorrer fatos ou eventos que influenciem ou mudem uma situação inicial. Portanto, o risco de não alcançar os resultados por causa de uma fraca equipe existe, mas não é considerado um fator externo.

Um outro exemplo é a parceria. Projetos de desenvolvimento quase sempre atuam dentro ou em torno de instituições públicas. Essas, por sua vez, quase sempre sofrem algum tipo de interferência política. Isso pode implicar na disponibilidade a tempo de recursos, na gerência das pessoas ou em diretrizes políticas. O planejamento tem que partir daquelas posições que são acordadas, mas são freqüentes algumas mudanças dessas posições ao longo do tempo. Igualmente, não podem ser consideradas como fatores externos possíveis mudanças na instituição responsável pelo projeto, porque colocaria em dúvida a confiabilidade da mesma. Já decisões políticas fora da instituição, alterações da legislação etc., são fatores pelos quais a organização dos projetos não pode assumir responsabilidade e, portanto, podem ser Suposições Importantes.

Se um determinado fator é uma Suposição Importante ou não, não pode ser determinado teoricamente, porque depende da situação concreta. Ele pode ser relevante em um caso e tornar-se suposição, e não ser relevante em outro. Por isso, suposições precisam ser avaliadas cuidadosamente antes de serem incluídas no QL.

Partindo do Resultado 1 do exemplo demonstrativo podemos imaginar que determinados desastres naturais podem comprometer o alcance do Objetivo do Projeto. Se essa suposição é relevante ou não, depende da situação. Numa região semi-árida não é de se surpreender que possa haver seca. Já o risco de haver inundações talvez seja muito remoto. Se não houver nenhuma probabilidade razoável de algum desastre natural acontecer, essa suposição pode ser inválida.

Onde há pouca água, geralmente existem "donos" da água que podem não se conformar com as mudanças planejadas pelo projeto. Por meio da análise da situação social e das experiências com casos semelhantes, a suposição "não há disputas excessivas pelo uso d'água" pode, ou não, ser relevante para o projeto. Embora não diretamente gerenciável, o projeto poderia observar a situação e eventualmente agir com medidas adicionais, se possível ou necessário. 
Com relação ao Resultado 2 pode ser relevante a Suposição "não há evasão de assessores capacitados". Tendo em vista uma perspectiva de desenvolvimento de longo prazo, seria necessário dispor de assessores capazes de apoiar adequadamente os agricultores. Porém, um problema frequiente é que pessoas melhor capacitadas deixam o seu local de trabalho em busca de melhores oportunidades e, talvez, melhores salários. Se isso ocorrer, o alcance do Objetivo do Projeto pode estar em jogo, embora as possibilidades da gerência sejam muito limitadas.

$\mathrm{O}$ mesmo se refere às suposições que dizem respeito ao preço do combustível ou ao preço do arroz. Se o financiamento dos investimentos dos agricultores está calculado na base de um determinado valor para custos operacionais, a mudança significativa desses custos pode inviabilizar o financiamento. Esses fatores não são controláveis pelo projeto, podem apenas ser observados. Um indicador de limitação como "mais que 5\%" ou "menos que $10 \%$ " pode servir de alerta que a gerência do projeto pode fazer junto aos responsáveis (no caso, o Ministério de Agricultura).

Com relação à capacitação dos agricultores, temos uma suposição que geralmente deve ser considerada, mas nem sempre precisa ser incluída. Por melhor que a equipe do projeto se desempenhe na capacitação, não se tem a garantia de que os capacitados realmente farão uso daquilo que era para aprender. Portanto, a assimilação do aprendizado está fora do controle da gerência do projeto. Mas se isso não acontecer, o Objetivo do Projeto não será alcançado.

As Suposições podem estar relacionadas a um determinado Resultado, a vários Resultados ou a todos. A sua localização correta depende apenas do nível em que se encontra.

Tendo realizado o exercício de Resultado + Suposição leva ao Objetivo do Projeto, o exercício é repetido ao nível superior. Supondo que se alcançou o Objetivo do Projeto, a suposição nesse nível seria aquele fator externo e importante que levaria ao Objetivo Superior.

No caso do exemplo demonstrativo, podemos imaginar que as melhorias alcançadas pelos agricultores da região do projeto atraem migrantes de outras regiões. Se isso ocorrer, as melhorias poderão ser comprometidas e o Objetivo Superior não seria alcançado. Trata-se de mais um fator que deveria ser monitorado pela gerência de projeto e, se a relevância for significativa, devem ser alertados os responsáveis.

A suposição em nível do Objetivo Superior tem como função indicar os fatores externos que ajudam a garantir a sustentabilidade do Objetivo Superior alcançado. No caso do exemplo, a suposição diz respeito à continuidade de uma determinada política agrícola. 


\subsection{Segunda coluna: Indicadores \\ Objetivamente Comprováveis}

\begin{tabular}{|c|c|c|c|}
\hline $\begin{array}{l}\text { Lógica da } \\
\text { Intervenção }\end{array}$ & $\begin{array}{l}\text { Indicadores Objetivamente } \\
\text { Comprováveis }\end{array}$ & $\begin{array}{l}\text { Fontes de } \\
\text { Comprovação }\end{array}$ & $\begin{array}{l}\text { Suposições } \\
\text { Importantes }\end{array}$ \\
\hline $\begin{array}{l}\text { Objetivo Superior: } \\
\text { Situação sócio-econômi- } \\
\text { ca da região melhorada. }\end{array}$ & $\begin{array}{l}\text { - Renda média aumentada em } \\
\text { x\% até o ano } 2002 \text {. } \\
\text { - Migração reduzida. }\end{array}$ & & \\
\hline $\begin{array}{l}\text { Objetivo do Projeto: } \\
\text { Agricultores aplicam } \\
\text { novas técnicas na pro- } \\
\text { dução de arroz. }\end{array}$ & $\begin{array}{l}\text { - Produtividade (ton./hectare) } \\
\text { aumentado em x\% na região } \\
\text { tal no ano } 2001 \text {, y\% no ano } \\
2002 \text { e z\% no ano } 2003 \text {. } \\
\text { - Produção de arroz tipo ex- } \\
\text { portação aumentada em x\%. }\end{array}$ & & \\
\hline $\begin{array}{l}\text { Resultados: } \\
\text { 1. Sistema de irrigação } \\
\text { implantado e funcio- } \\
\text { nando. } \\
\text { 2. Serviço de Assistência } \\
\text { Agrícola está fortale- } \\
\text { cido. } \\
\text { 3. Financiamento } \\
\text { para mecanização é } \\
\text { facilitado. } \\
\text { 4. Sistema de } \\
\text { comercialização } \\
\text { implantado e } \\
\text { funcionando. } \\
\text { 5. Agricultores } \\
\text { capacitados. }\end{array}$ & $\begin{array}{l}\text { - Na região são implantados } \\
60 \mathrm{~km} \text { de canais de irrigação } \\
\text { e } 12 \text { bombas elétricas } \\
\text { de potência média até } \\
\text { 9/2000. } \\
\text { - X hectares de terras são } \\
\text { servidos em } 12 / 2000 . \\
\text { - Ociosidade do sistema } \\
\text { de irrigação é, no máximo, } \\
24 \text { h/mês. } \\
\text { - Relação do no de assessores/ } \\
\text { agricultores. } \\
\text { - No mínimo, } 2 \text { visitas } \\
\text { técnicas/mês por agricultor. } \\
\text { - Quantidade de insumos } \\
\text { solicitada em x\%. } \\
\text { - Valor de créditos concedidos. } \\
\text { - No de créditos concedidos. } \\
\text { - Inadimplência abaixo de } 5 \% \text {. } \\
\text { - Esquema de comercialização } \\
\text { é definido em } 2 / 2001 \text {, espe- } \\
\text { cificando locais, datas, paga- } \\
\text { mento etc. } \\
\text { - Volumes comercializados: } \\
2001 \text { - x; } 2002 \text { - y; } 2003 \text { - z } \\
\text { toneladas. } \\
\text { - No de agricultores treinados } \\
\text { em novas técnicas de cultivo } \\
\text { de arroz. } \\
\text { to e seu aproveitamento. }\end{array}$ & & \\
\hline
\end{tabular}


A função dos indicadores é esclarecer, evidenciar e concretizar o

que se pretende alcançar com cada resultado ou objetivo. Durante o processo de elaboração dos indicadores, os planejadores são obrigados a refletir sobre cada item, seu significado e seu valor.

Um indicador é mais do que uma meta quantitativa. Embora sendo esta também uma das caraterísticas, o indicador não pode estar limitado a dizer, quanto de algo se pretende obter. Idealmente, o indicador fornece informações sobre cinco aspectos: quantidade, qualidade, tempo (prazo), local e beneficiários. Dificilmente um único indicador contém todas essas informações e por isso é comum utilizar um conjunto de indicadores para se aproximar à descrição "espírito" de um determinado resultado ou objetivo.

Os indicadores estabelecidos no QL estão sempre relacionados ao desempenho e, portanto, podem ser considerados indicadores de desempenho. Mas o caráter dos indicadores em nível de resultados é diferente dos indicadores em nível dos objetivos.

Se os resultados têm que ser gerenciáveis, os seus respectivos indicadores também o são. Isso significa que estes indicadores são indicadores de acompanhamento ou de resultados (output indicators). Assim eles descrevem, de forma detalhada, as características daqueles bens ou serviços que são produzidos pelo projeto. São, portanto, metas físicas e temporais, são especificações de qualidade dos locais (se necessário) e podem mencionar os beneficiários envolvidos. Esses indicadores não descrevem os efeitos que se espera dos bens ou serviços, já que estes não são gerenciáveis, porque são dependentes de fatores externos das suposições.

Por exemplo, no Resultado 5, Agricultores Capacitados, pode-se especificar não apenas o número, mas também o tipo e o grau de aproveitamento que se espera. Mas não é possível definir nesse indicador, como o indivíduo aplicará o seu novo conhecimento na prática.

Os efeitos, especialmente as mudanças, manifestam-se no nível imediatamente superior, no Objetivo do Projeto. Por isso, os indicadores neste nível são indicadores de efeito. A pergunta aqui é: como se pode reconhecer que o Objetivo do Projeto foi alcançado? Esses indicadores descrevem, portanto, quais os benefícios que se espera em função de um novo comportamento ou de novas práticas. Conforme o exemplo demonstrativo, espera-se que o desenvolvimento seja alavancado por meio de novas práticas dos agricultores, porque antes havia sido analisado e descoberto que práticas rudimentares evitaram que a produção pudesse crescer.

É freqüente encontrar numa situação dessas um objetivo do tipo aumento da produção ou aumento da produtividade. No entanto, com um 
objetivo dessa natureza permaneceria a pergunta: como alcançá-lo? Os resultados (infra-estrutura, insumos e capacitação) são necessários para isso, mas sem que houvesse uma mudança nas práticas e, com isso, uma mudança de comportamento dos agricultores, o aumento não seria alcançável. Embora esta mudança possa ser subentendida, na realidade, ela pode ser a parte mais difícil de se alcançar. Na prática, muitos projetos de desenvolvimento fracassam porque não levam suficientemente em consideração o fator comportamental dos grupos-alvo.

Por isso, o exemplo demonstrativo considera o aumento da produtividade como um indicador e não como um objetivo, porque esse fato indicaria a mudança desejada e necessária na prática agrícola. Com isso, o enfoque do projeto está orientado para uma questão do desenvolvimento e não apenas para uma meta quantitativa. Essa meta, embora desejável, é somente alcançável pelas mudanças nas pessoas.

Um outro exemplo de indicador do Objetivo do Projeto diz respeito à qualidade do produto. Além disso, devem ser estabelecidos marcos temporais.

Obviamente, a gerência do projeto não está totalmente isenta do alcance do objetivo e dos seus respectivos indicadores. A diferença é que esses efeitos servem mais como orientação, tanto para a gerência como para os outros envolvidos, principalmente o grupo-alvo.

O mesmo acontece com os indicadores no nível do Objetivo Superior. Para este, o projeto apenas contribui, embora de forma significativa. Na hora de elaborar indicadores para o Objetivo Superior, muitas vezes se descobre que ele é alto demais, quase abstrato. Porque se não é possível mensurar a contribuição do projeto para o alcance do Objetivo Superior, a sua função de delimitar o ambiente e o contexto do projeto não pode ser cumprida. 
4.4. Terceira Coluna: Fontes de Comprovação

\begin{tabular}{|c|c|c|c|}
\hline $\begin{array}{l}\text { Lógica da } \\
\text { Intervenção }\end{array}$ & $\begin{array}{l}\text { Indicadores Objetivamente } \\
\text { Comprováveis }\end{array}$ & $\begin{array}{l}\text { Fontes de } \\
\text { Comprovação }\end{array}$ & $\begin{array}{l}\text { Suposições } \\
\text { Importantes }\end{array}$ \\
\hline OS & $\begin{array}{l}\text { (para o Objetivo Superior) } \\
\text { - Renda média aumentada em } \\
\text { x\% até o ano } 2002 \text {. } \\
\text { - Migração reduzida. }\end{array}$ & - Censo anual & \\
\hline OP & $\begin{array}{l}\text { (para o Objetivo do Projeto) } \\
\text { - Produtividade (ton./hectare) } \\
\text { aumentado em x\% na região tal } \\
\text { no ano } 2001, \text { y } \% \text { no ano } 2002 \\
\text { e z\% no ano } 2003 \text {. } \\
\text { - Produção de arroz tipo } \\
\text { exportação aumentada em x\%. }\end{array}$ & $\begin{array}{l}\text { - Censo agrícola } \\
\text { - Documentação do } \\
\text { projeto }\end{array}$ & \\
\hline $\mathrm{R} 1$ & $\begin{array}{l}\text { (para os Resultados) } \\
\text { - Na região são implantados } \\
60 \mathrm{~km} \text { de canais de irrigação } \\
\text { e } 12 \text { bombas elétricas de } \\
\text { potência média até } 9 / 2000 \text {. } \\
\text { - X hectares de terras são servi- } \\
\text { dos em } 12 / 2000 . \\
\text { - Ociosidade do sistema } \\
\text { de irrigação é, no máximo, } \\
\text { 24h/mês. }\end{array}$ & $\begin{array}{l}\text { - Livro de obras } \\
\text { - Vistoria local } \\
\text { - Livro de ocorrências }\end{array}$ & \\
\hline $\mathrm{R} 2$ & $\begin{array}{l}\text { - Relação do nº de assessores/ } \\
\text { agricultores. } \\
\text { - No mínimo, } 2 \text { visitas } \\
\text { técnicas/mês por agricultor. } \\
\text { - Quantidade de insumos solicitada. }\end{array}$ & $\begin{array}{l}\text { - Min. de Agricultura } \\
\text { - Relatórios dos } \\
\text { assessores } \\
\text { - Livros de solicitação }\end{array}$ & \\
\hline R3 & $\begin{array}{l}\text { - Valor de créditos concedidos. } \\
\text { - } \mathrm{N}^{\circ} \text { de créditos concedidos. } \\
\text { - Inadimplência abaixo de } 5 \% \text {. }\end{array}$ & $\begin{array}{l}\text { - Documentação do } \\
\text { Fundo Rotativo }\end{array}$ & \\
\hline $\mathrm{R} 4$ & $\begin{array}{l}\text { - Esquema de comercialização } \\
\text { é definido em 2/2001, espe- } \\
\text { cificando locais, datas, paga- } \\
\text { mento etc. } \\
\text { - Volumes comercializados: } 2001 \text { - } \\
\text { x; } 2002 \text { - y; } 2003 \text { - z toneladas. }\end{array}$ & $\begin{array}{l}\text { - Documentação do } \\
\text { Dept- de } \\
\text { Comercialização }\end{array}$ & \\
\hline R5 & $\begin{array}{l}\text { - } \mathrm{N}^{\circ} \text { de agricultores treinados em } \\
\text { novas técnicas de cultivo de } \\
\text { arroz. } \\
\text { - Tipo e duração do treinamento e } \\
\text { seu aproveitamento. }\end{array}$ & $\begin{array}{l}\text { - Relatórios dos } \\
\text { instrutores } \\
\text { - Documentação } \\
\text { do projeto }\end{array}$ & \\
\hline
\end{tabular}


A elaboração dos indicadores estimula os planejadores a imaginar como será caraterizada a situação futura e desejada após o término do projeto. Mas, na verdade, não passa de imaginação, porque ninguém sabe ao certo como será a realidade. Para evitar que essa imaginação vá longe demais, o QL inclui a coluna das Fontes de Comprovação.

As Fontes de Comprovação para os indicadores do Objetivo Superior são geralmente fontes externas e independentes do projeto. Se a intenção do projeto é provocar efeitos significativos além das suas limitações gerenciais, esses efeitos devem se manifestar de alguma forma. No caso do exemplo, podemos imaginar que os efeitos se refletem nas estatísticas oficiais (se houver) ou talvez em pesquisas acadêmicas.

Para os Indicadores do Objetivo do Projeto é igualmente desejável que existam fontes independentes e externas ao projeto, mas as informações têm que ser mais específicas e a relação dos dados e das tendências com a atuação do projeto é fundamental. Adicionalmente podem ser utilizadas informações geradas pelo próprio projeto. Levando em consideração que a evidência do alcance do Objetivo do Projeto tem uma importância especial, pode-se considerar necessário criar mecanismos para averiguar esses indicadores, desde que os custos possam ser justificados.

As fontes relacionadas aos indicadores dos resultados são, na sua maioria, fontes do próprio projeto, dos seus parceiros ou, por algum outro motivo, próximas ao projeto. Isso requer uma documentação completa e contínua de todos os processos e atividades planejados e/ou realizados e essas fontes são disponibilizadas para avaliações e para lições aprendidas ao final do projeto.

\section{O Quadro Lógico como Instrumento de Gerenciamento de Projeto}

O Quadro Lógico é apenas um instrumento para gerenciar projetos. Para ser eficaz, ele precisa ser aplicado adequadamente, complementado por outros instrumentos de gerenciamento, bem como integrado num sistema mais amplo de gerenciamento.

A aplicação adequada significa que, por um lado, é preciso ser seguida a estrutura lógica, mas por outro, que é preciso ser flexível o suficiente para levar devidamente as especificidades de cada projeto em consideração. A complementação com outros instrumentos de gerenciamento é necessária porque o QL não cobre todos os aspectos relevantes, nem tem essa pretensão. E por fim, a integração do QL num sistema de gerenciamento 
com estrutura organizacional e procedimentos administrativos definidos é fundamental para ele poder desdobrar o seu potencial.

A descrição a seguir de diversos aspectos de gerenciamento de projeto não é exaustiva, ela visa apenas contextualizar o instrumento.

\section{Evolução do Quadro Lógico de um projeto}

O Quadro Lógico é uma matriz que define quais as relações lógicas entre os diversos campos. No entanto, o preenchimento do quadro não é uma atividade curta e única que resulta no quadro preenchido e com isso em um projeto completamente planejado. A matriz pode ser utilizada como instrumento para a estruturação das idéias em torno do futuro projeto, mas não deve ser preenchida mecanicamente.

Na prática, o QL evolui na mesma proporção que a concretização do projeto evolui. Num primeiro momento, pode ser utilizada apenas a Lógica da Intervenção para experimentar alguns ensaios sobre o rumo e o escopo de um possível projeto. Levando em consideração alguns dados básicos como, por exemplo, o contexto, a organização responsável e os possíveis recursos, é possível esboçar o Objetivo Superior e o Objetivo do Projeto e os Resultados que seriam necessários. Nesta etapa ainda não é necessário definir indicadores ou suposições.

Tendo esboçada uma idéia geral do projeto, pode-se preparar e realizar a análise da situação, requisito indispensável para um desenho adequado de um projeto. Quais os instrumentos apropriados para isso e como a forma e a profundidade necessárias podem variar de caso para caso. De todo modo, conhecer os problemas, os atores e seus interesses, os riscos, mas também as alternativas dos diversos objetivos é fundamental.

Baseado numa análise detalhada da situação que justifica a realização de um projeto e que se deseja mudar, o QL ganha cada vez mais corpo e estrutura. Nessa fase de concepção já devem ser elaborados indicadores e suposições, embora eles possam ainda ter um caráter um pouco genérico. Mesmo assim, o produto poderá ser suficientemente informativo para que os responsáveis possam tomar a decisão sobre a continuidade.

Tomada a decisão favorável, o planejamento definitivo precisa ser preparado, o que pode revelar a necessidade de mais análises ou um maior detalhamento. É na fase do planejamento que o QL ganha a sua forma mais completa, com o maior grau de detalhamento das informações nos indicadores, nas fontes e nas suposições. Mas em cada uma dessas 
fases é possível que haja alterações e correções, até que a estrutura pareça sem falhas lógicas e sem fatores de risco inaceitáveis.

Mas isso não significa que o QL virou lei nem que o projeto será implementado sem problemas. O Quadro Lógico é um mapa de orientação para a gerência e sua equipe e ainda representa uma espécie de acordo entre os diversos interessados sobre o rumo do projeto e os compromissos envolvidos. Por outro lado, o QL deve ser utilizado de forma flexível e adequada às circunstâncias. Apenas quando os parâmetros básicos não são mais válidos, deve-se rever o planejamento e todo o seu conteúdo.

\section{Planejamento Global e Planejamento Operacional}

Como mapa geral, o QL não define os aspectos operacionais para o projeto. Mas se ele for bem estruturado, todas as atividades principais definidas são aquelas que são necessárias para o alcance dos resultados $\mathrm{e}$, com isso, formam a base do planejamento operacional.

Existem várias formas de planejamento operacional, embora todas sigam a mesma lógica: a decomposição. Atividades complexas são desdobradas em subatividades, se essas forem ainda demasiado complexas são desdobradas em outras subatividades, e assim por diante, até que se alcance o nível de detalhamento desejado ou necessário para realizar as estimativas definitivas dos recursos necessários e para organizar e distribuir o trabalho. Se a operacionalização consiste numa simples lista de atividades ou de uma estrutura analítica complexa utilizando software específico depende exclusivamente das necessidades do projeto. O QL apenas define os elementos do plano operacional (Resultados) e indica um primeiro nível de detalhamento (Atividades Principais).

Mas é importante lembrar que o planejamento operacional não é completo baseando-se apenas nas atividades principais definidas no QL. Essas atividades devem cobrir todas aquelas que são necessárias para o alcance do Objetivo do Projeto do ponto de vista do conteúdo, mas não são consideradas as atividades gerenciais. Para a alocação dos recursos, especialmente dos recursos humanos, este último aspecto é importante e deve ser considerado no plano operacional ou num plano gerencial específico. 


\section{O Quadro Lógico e o seu contexto}

$\mathrm{O}$ QL responde a um grande número de requisitos que precisam ser conhecidos e definidos para desenhar um projeto, mas ele não responde a todos. Em primeiro lugar, é importante lembrar que um projeto precisa de uma estrutura organizacional onde são definidas responsabilidades, procedimentos e o próprio modo de gerenciar. Um projeto pode estar integrado dentro das estruturas organizacionais existentes, ou pode tornar-se, temporariamente, uma unidade organizacional própria.

Segundo, para gerenciar um projeto é necessária uma série de outros instrumentos ou subsistemas, como, por exemplo, os de informações gerenciais ou de monitoramento e avaliação. O QL apenas apóia estes sistemas, mas não os substitui.

\section{Figura 8: O Quadro Lógico no contexto do projeto}

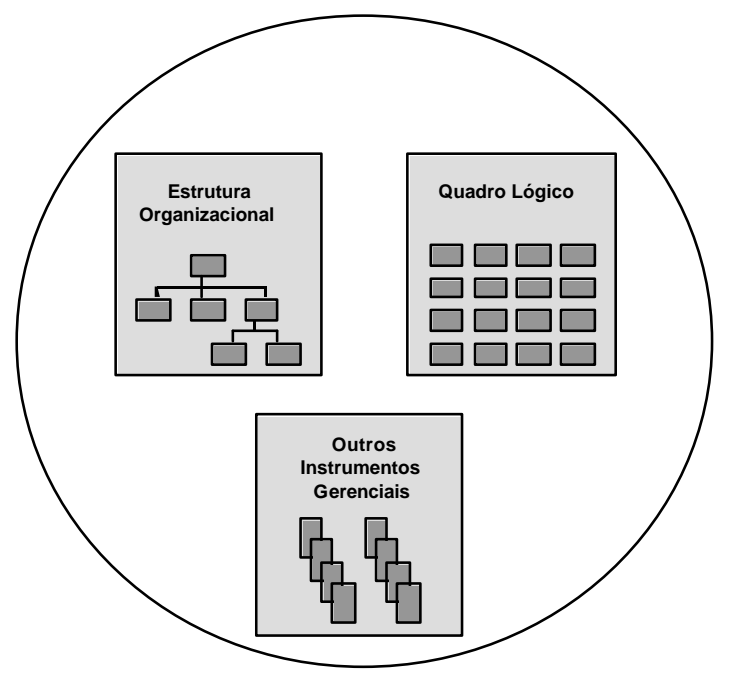

\section{O Quadro Lógico para programas}

O Quadro Lógico foi elaborado para ajudar o planejamento e gerenciamento de Projetos de Desenvolvimento. Mas, na realidade, muitos destes chamados projetos são programas, porque se desdobram em subprojetos, em componentes, ou simplesmente em outros projetos.

A princípio, nada impede a utilização do QL para desenhar um programa, já que a lógica básica é a mesma: são utilizados recursos para produzir algo, para produzir efeitos positivos no desenvolvimento. Para isso, geralmente é recomendado aplicar o QL em forma de cascata. O Objetivo do Programa corresponde ao Objetivo Superior de vários projetos que, por sua vez, têm seus próprios objetivos e seus respectivos resultados. Cada objetivo de um projeto poderia corresponder a um dos resultados do programa. 
Enquanto esta lógica pode estar perfeitamente coerente, é importante alertar para as implicações gerenciais. No QL de um projeto existe uma clara linha divisória entre a parte gerenciável (insumos, atividades e resultados) e a parte não-gerenciável (objetivos do projeto e superior).

Aplicado esse mesmo raciocínio para um QL de um programa, deve ser averiguado se os resultados do programa são, de fato, gerenciáveis. Se esses resultados são produzidos pelo esforço e desempenho de outras organizações, a gerência do programa pode-se encontrar numa situação de dependência. Nesse caso, deve ser esclarecido nos indicadores, se estes se referem apenas ao desempenho da gerência do programa ou aos efeitos procedentes dos projetos que compõem o programa.

Por outro lado, se as relações e responsabilidades estão bem definidas, o QL pode servir perfeitamente para estruturar programas e alinhar os seus diversos componentes ou projetos.

Figura 9: Responsabilidade pelo gerenciamento

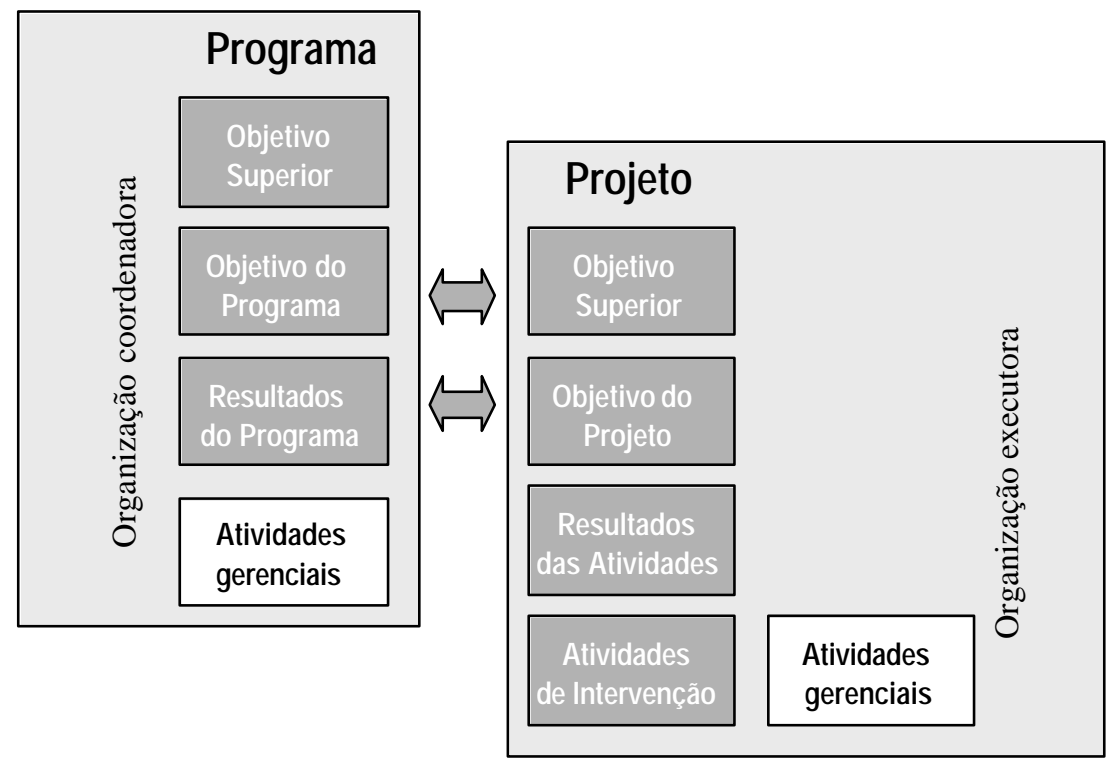

\section{O Quadro Lógico e o PMBOK Guide ${ }^{16}$}

Gerenciamento de projeto é muito mais amplo do que a aplicação de um único instrumento, por mais complexo que ele seja. O QL é um dos instrumentos relativamente complexos porque sintetiza diversos processos analíticos e os traduz em uma visão futura do projeto, seus benefícios e mudanças esperadas. A partir do planejamento do projeto, o QL continua tendo grande importância para o gerenciamento, especialmente para o monitoramento e a avaliação. Mas quando relacionado com o Guia do Universo de Conhecimento em Gerenciamento de Projeto (PMBOK 
Guide), por exemplo, podemos verificar que o QL não responde a todos os aspectos de gerenciamento de projeto, que são organizados em Áreas de Conhecimento pelo Project Management Institute $(P M I)^{17}$.

\begin{tabular}{|c|c|}
\hline $\begin{array}{l}\text { Área de } \\
\text { Conhecimento }\end{array}$ & Resposta do Quadro Lógico \\
\hline Escopo & $\begin{array}{l}\text { O escopo bem definido é uma das principais } \\
\text { preocupações do QL. A Lógica da Intervenção trata } \\
\text { dele exaustivamente, inclusive considerando as duas } \\
\text { dimensões do escopo: aquela que é diretamente } \\
\text { gerenciável (resultados) e aquela que é esperada como } \\
\text { efeito do projeto (objetivo). } \\
\text { O estabelecimento das atividades principais relaciona- } \\
\text { das a cada resultado também contribui para uma delimi- } \\
\text { tação precisa e para o gerenciamento do escopo. }\end{array}$ \\
\hline Tempo & $\begin{array}{l}\text { Para cada objetivo e resultados são estabelecidos um } \\
\text { ou mais indicadores. Uma das caraterísticas do indica- } \\
\text { dor é a sua dimensão tempo que permite definir pra- } \\
\text { zos e milestones, e acompanhá-los durante o ciclo do } \\
\text { projeto. } \\
\text { O plano operacional, baseado no QL detalha mais os } \\
\text { prazos e as datas. }\end{array}$ \\
\hline Custo & $\begin{array}{l}\text { As principais atividades do QL dão uma primeira } \\
\text { base para realizar estimativas de custos. O seu } \\
\text { detalhamento acontece no plano operacional. }\end{array}$ \\
\hline Qualidade & $\begin{array}{l}\text { Qualidade é uma das cinco caraterísticas } \\
\text { do indicador. }\end{array}$ \\
\hline Recursos Humanos & $\begin{array}{l}\text { As atividades principais dão uma base para a estima- } \\
\text { tiva de recursos humanos necessários, mas o QL não } \\
\text { se propõe especificamente a gerenciar RH. A aplica- } \\
\text { ção do QL requer uma estrutura organizacional ade- } \\
\text { quada complementar à estruturação do projeto. }\end{array}$ \\
\hline Comunicação & $\begin{array}{l}\text { Faz parte da estrutura organizacional e o seu funcio- } \\
\text { namento não é considerado especificamente pelo QL. } \\
\text { No entanto, o próprio QL é um instrumento de comu- } \\
\text { nicação. }\end{array}$ \\
\hline Risco & $\begin{array}{l}\text { O QL dá atenção especial a riscos externos, ou seja, } \\
\text { fatores que estão fora do controle gerencial do projeto, } \\
\text { mas que são importantes para o êxito do projeto. Esses } \\
\text { riscos são analisados e considerados na coluna das } \\
\text { suposições. As suposições podem ser especificadas } \\
\text { com indicadores que devem ser monitorados. }\end{array}$ \\
\hline Aquisição e contratos & O QL não considera esta área. \\
\hline Integração & $\begin{array}{l}\text { A descrição do QL, dos seus diversos elementos e } \\
\text { das suas inter-relações, que é um documento à parte, } \\
\text { e o monitoramento da sua validade ao longo do tem- } \\
\text { po, visam garantir a integração, dentro de uma estru- } \\
\text { tura organizacional definida para o projeto. }\end{array}$ \\
\hline
\end{tabular}


Cabe lembrar que os tipos de projetos considerados pelo PMI são principalmente projetos industriais. Projetos de desenvolvimento, sejam eles gerenciados por um órgão público nacional ou sejam projetos de

cooperação com órgãos internacionais, geralmente não seguem a lógica do mercado. Por outro lado, os riscos políticos ou mesmo sociais são maiores.

O tipo de projeto bastante comum também no setor privado e que tem caraterísticas semelhantes é o projeto de desenvolvimento organizacional. Neste caso, também não são os produtos tangíveis (por exemplo, melhores equipamentos) ou alguns serviços (por exemplo, capacitação) que já garantem o êxito do projeto. São as mudanças comportamentais das pessoas envolvidas, quando utilizam melhor os produtos de um projeto de desenvolvimento organizacional (equipamentos, capacitação etc.), que podem mudar a cultura de uma organização e assim a desenvolverem. Apesar deste potencial, no vasto acervo de ferramentas consideradas pelo PMI, o QL não tem nenhum lugar de destaque ${ }^{18}$.

\section{Benefícios do Quadro Lógico}

O uso do QL para planejar e gerenciar projetos pode trazer uma série de benefícios para a organização e, principalmente, para os usuários dos benefícios que o projeto produzir. Dentro das funções gerenciais, as que são principalmente apoiadas pelo QL são: planejamento, comunicação e controle.

O processo do planejamento compreende todos os aspectos da concepção, da análise, da criação de idéias e propostas e, principalmente, da definição do lugar aonde se pretende chegar: os objetivos. Poucos instrumentos de gerenciamento se preocupam tanto com a operacionalização dos objetivos. Isso não diz respeito apenas à busca de formulações mais precisas possíveis, mas também à utilização de indicadores que tornam as visões mensuráveis. A sua elaboração é um processo difícil, mas necessário e, quando bem realizado, um investimento valioso para a implementação.

Quando aplicadas todas as ferramentas para a elaboração do QL, tais como workshops participativos, visualização, diagnósticos qualitativos etc., as pessoas e as organizações envolvidas entendem melhor porque essa opção e não uma outra, o que fortalece a identificação com o produto QL e seu conteúdo, e facilita a comunicação durante todo o processo da implementação. É evidente que a elaboração de um QL não significa que todos os problemas de entendimento estejam resolvidos, mas a sua solução torna-se mais fácil.

A vantagem de um QL não diz respeito apenas aos diversos atores envolvidos num projeto, mas também à comunicação interna. Ele é um 
instrumento que ajuda o gerenciamento da equipe por meio dos objetivos, indicadores e das atividades previamente definidas. A chance de que todos os membros de uma equipe andem na mesma direção é maior.

E, como mapa geral do percurso do projeto, o QL facilita também o controle. Além da Lógica da Intervenção, do Plano Operacional e dos Indicadores, o QL considera riscos externos pelas suposições. Com todos esses elementos constrói-se uma base para um sistema de informações gerenciais e para o monitoramento e a avaliação. A discussão e definição prévias do que constitui o êxito do projeto ajudam a orientar a caminhada para chegar-se ao objetivo.

Mas o QL não é um instrumento de fácil domínio. Um documento da Lewis Grant Associates o chama de enganosamente simples, porque a sua estrutura básica é, de fato, simples e plausível, mas preencher os 16 campos da matriz de tal forma que o projeto seja completo e coerente exige bastante disciplina e experiência. Uma das dificuldades está no fato de que cada projeto é diferente do outro e há pouquíssimos elementos que podem ser copiados de um caso para um outro.

Outras dificuldades encontradas na prática são a aplicação rigorosa da lógica (geralmente, ser um pouco lógico, não funciona), os antigos hábitos de estruturar projetos (incluir muitos objetivos para evitar que alguém possa se sentir excluído) e a despreocupação pela questão da gerenciabilidade (depois a gente vê como resolver).

Como para muitos outros instrumentos, para o QL também é fundamental a sua adequada aplicação. Não é recomendável trabalhar com ele em casos reais sem uma devida preparação que inclui tanto conhecimento teórico como experiência prática. Por isso, as organizações que incorporaram o QL na formatação dos seus projetos e nos seus procedimentos de gerenciamento fazem uso de especialistas na metodologia e facilitação da aplicação. 


\section{Anexo 1: Termos usados em diversos modelos de Quadro Lógico}

A terminologia utilizada nos diversos modelos de Quadro Lógico não é unificada. Em alguns casos trata-se de traduções imprecisas do inglês ou alemão, mas com o mesmo sentido. Em outros casos existem diferenças nos conceitos. A seguir, apresentamos a terminologia recomendada e utilizada neste texto e alguns termos semelhantes encontrados na literatura:

\begin{tabular}{|c|c|c|}
\hline $\begin{array}{l}\text { Termo } \\
\text { recomendado }\end{array}$ & $\begin{array}{l}\text { Termos análogos } \\
\text { em português }\end{array}$ & Termos em inglês \\
\hline $\begin{array}{l}\text { Atividades } \\
\text { Principais }\end{array}$ & Atividades; & Activities; \\
\hline $\begin{array}{l}\text { Fontes de } \\
\text { Comprovação }\end{array}$ & $\begin{array}{l}\text { Fontes de Verificação; } \\
\text { Meios de Verificação; }\end{array}$ & $\begin{array}{l}\text { Means of Verification; } \\
\text { Monitoring and Evaluation; }\end{array}$ \\
\hline $\begin{array}{l}\text { Indicadores } \\
\text { Objetivamente } \\
\text { Comprováveis }\end{array}$ & $\begin{array}{l}\text { Indicadores Objetivamente } \\
\text { Verificáveis; Indicadores } \\
\text { Facilmente Verificáveis; }\end{array}$ & $\begin{array}{l}\text { Indicators; Objectively } \\
\text { Verifiable Indicators; Key } \\
\text { Performance Indicators; }\end{array}$ \\
\hline $\begin{array}{l}\text { Lógica da } \\
\text { Intervenção }\end{array}$ & Descrição Sumária; Descrição & $\begin{array}{l}\text { Hierarchy of objectives; } \\
\text { Strategy; }\end{array}$ \\
\hline $\begin{array}{l}\text { Objetivo } \\
\text { do Projeto }\end{array}$ & Objetivo Específico; & $\begin{array}{l}\text { Purpose; Outcome; } \\
\text { Immediate Objective; } \\
\text { Project Development } \\
\text { Objective; }\end{array}$ \\
\hline $\begin{array}{l}\text { Objetivo } \\
\text { Superior }\end{array}$ & Diretriz; Objetivo Global; & $\begin{array}{l}\text { Goal; Development } \\
\text { Objective; }\end{array}$ \\
\hline $\begin{array}{l}\text { Quadro } \\
\text { Lógico }\end{array}$ & $\begin{array}{l}\text { Matriz de Planejamento de } \\
\text { Projeto; Marco Lógico; Matriz } \\
\text { Lógica; Matriz de Estrutura } \\
\text { Lógica; }\end{array}$ & $\begin{array}{l}\text { Logical Framework, } \\
\text { Logframe; Project Planning } \\
\text { Matrix; }\end{array}$ \\
\hline Resultados & $\begin{array}{l}\text { Produtos; Resultados Esperados; } \\
\text { Resultados Intermediários; }\end{array}$ & $\begin{array}{l}\text { Outputs; Results; } \\
\text { Deliverables; }\end{array}$ \\
\hline $\begin{array}{l}\text { Suposições } \\
\text { Importantes }\end{array}$ & $\begin{array}{l}\text { Pressupostos; Hipóteses; } \\
\text { Hipóteses de Referência; }\end{array}$ & $\begin{array}{l}\text { Assumptions; Critical } \\
\text { Assumptions; External } \\
\text { Factors; }\end{array}$ \\
\hline
\end{tabular}

Observação: O uso dos termos marcados em itálico não é recomendado. 


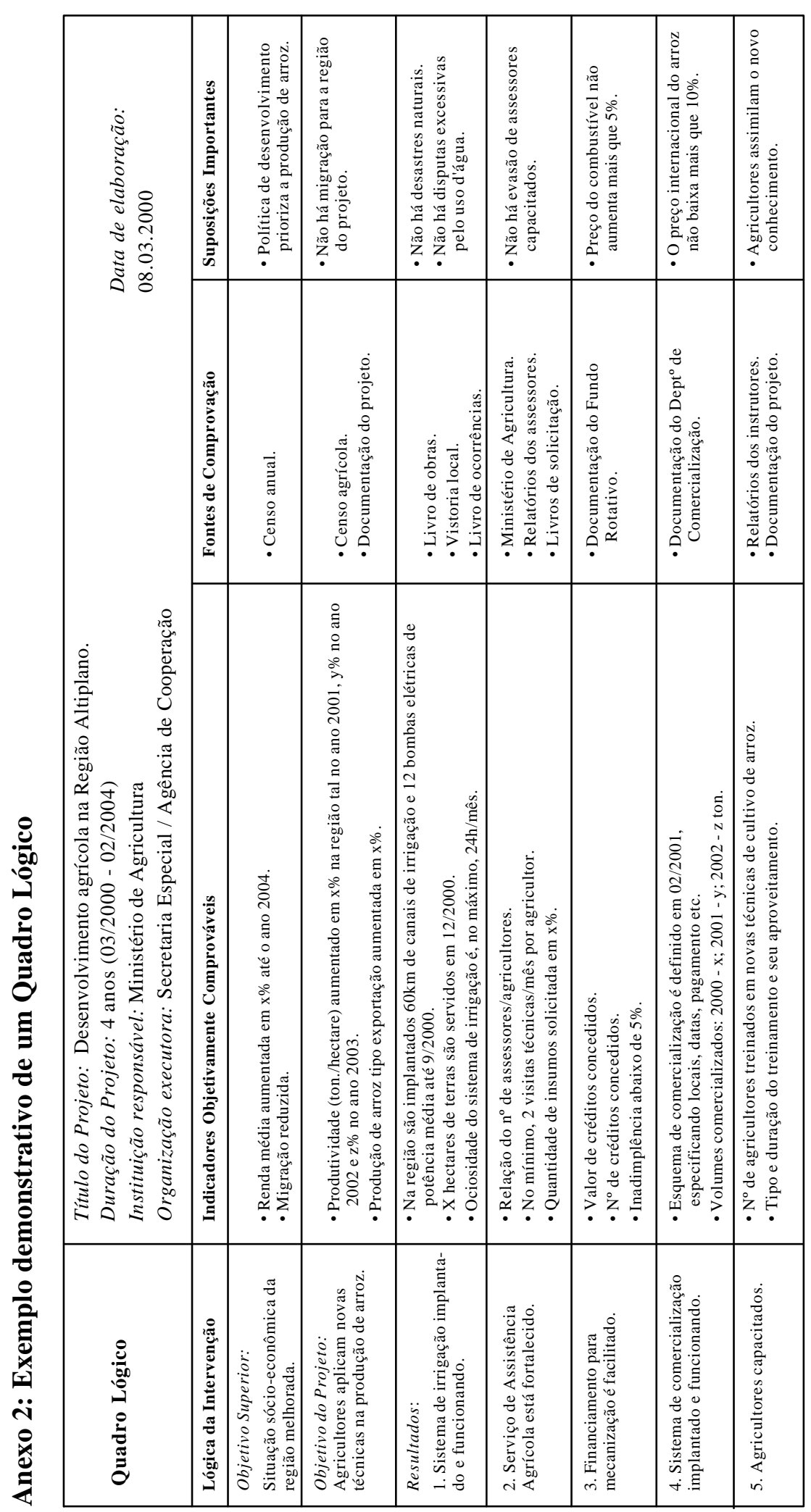




\section{Anexo 3: Áreas de Conhecimento (segundo PMBOK Guide) $^{19}$}

O PMBOK Guide descreve aquele conjunto de conhecimentos em gerenciamento de projeto que é geralmente aceito. Geralmente aceito significa que o conhecimento e as práticas descritas são aplicáveis na maioria dos projetos e na maioria dos casos e que existe um amplo consenso sobre seus valores e a sua utilidade. O conjunto do conhecimento é organizado em nove áreas de conhecimento. Algumas destas áreas podem ser menos relevantes em alguns projetos do que em outros, dependendo do tipo, do enfoque ou do tamanho do projeto. No entanto, as caraterísticas básicas são sempre as mesmas e a pertinência de cada área deveria ser pelo menos contemplada ${ }^{20}$.

Gerenciamento do Escopo: descreve os processos necessários para assegurar que o projeto inclui todo e apenas o trabalho necessário para concluir o projeto com êxito, quais sejam: iniciação, planejamento do escopo (abrangência), definição do escopo, verificação do escopo e o controle das mudanças no escopo durante o projeto.

Gerenciamento do Tempo: descreve os processos necessários para assegurar a conclusão do projeto no prazo estipulado. São considerados os processos de definição das atividades, seqüenciamento das atividades, estimativa da duração das atividades, elaboração do cronograma e controle do cronograma.

Gerenciamento do Custo: descreve os processos necessários para assegurar a conclusão do projeto dentro do orçamento previsto e aprovado. Para isso precisa do planejamento dos recursos, estimativa dos custos, elaboração do cronograma financeiro e controle dos gastos.

Gerenciamento da Qualidade: descreve os processos necessários para assegurar que o projeto vai satisfazer as necessidades para as quais ele foi iniciado. Isso inclui planejamento da qualidade, garantia da qualidade e controle de qualidade.

Gerenciamento dos Recursos Humanos: descreve os processos necessários para aproveitar, de forma mais eficiente, o pessoal envolvido no projeto. Inclui planejamento organizacional, contratação de pessoal e desenvolvimento de equipe.

Gerenciamento da Comunicação: descreve os processos necessários para assegurar a tempo e de forma adequada a geração, coleta, disseminação, armazenamento e arquivamento final das informações sobre o projeto. Para isto deve haver planejamento da comunicação, distribuição de informações, relatório de desempenho e o fechamento administrativo.

Gerenciamento do Risco: descreve os processos relacionados à identificação, análise e tratamento de riscos do projeto. Os processos são 
identificação, quantificação, elaboração de respostas e controle de tratamento dos riscos.

Gerenciamento da Aquisição e dos Contratos: descreve os processos necessários para adquirir bens e serviços de fora da organização executora do projeto. Para isso, realiza-se planejamento das necessidades de aquisição, planejamento das solicitações, seleção dos fornecedores, administração dos contratos e fechamento dos contratos.

Gerenciamento da Integração: descreve os processos necessários para assegurar que os vários elementos de um projeto sejam coordenados adequadamente. Inclui a elaboração do plano do projeto, sua implementação e o controle geral de todo o processo. $\mathrm{O}$ gerenciamento da integração é o parêntese que integra todas as demais áreas.

\section{| Notas}

1 Este histórico está principalmente baseado em: GTZ (1998), Kohnert/Preub/SAuer, 1992 e Wheatley, 1984.

2 O MBO já vinha sendo amplamente aplicado, com relativo sucesso, tanto no meio militar como no setor privado.

3 O Enfoque Quadro Lógico (Logical Framework Approach) é uma metodologia para desenhar projetos por meio de um processo estruturado que resulta em um documento resumido e em forma de uma matriz, o QL (Logical Framework ou Logframe). Aqui tratamos apenas do QL e da sua estrutura como instrumento de gerenciamento de projeto.

4 O termo inglês management tem várias traduções em português, e não se encontra um uso sistemático na literatura especializada. Management pode significar gerência, gerenciamento, gestão ou administração. Para o conceito Project Management usamos aqui Gerenciamento de Projeto. Gerência refere-se às pessoas (ou grupos) que executam funções gerenciais, às suas atribuições e papéis. O termo gestão entendemos como administração no sentido latu, porque nele geralmente predomina uma conotação política. Muitas vezes, o termo gestão é vinculado ao gestor superior (p. ex., o Prefeito) ou se refere ainda a um determinado período (p. ex., uma legislatura). O termo administração não usamos no contexto de projetos pela conotação burocrática que ele tem. Ver PFeIFFer, 1999.

5 No método ZOPP, o Quadro Lógico é conhecido como Matriz de Planejamento de Projeto (MPP). Às vezes encontra-se também o termo Marco Lógico. Este uso possivelmente vem do espanhol, onde marco tem o significado de quadro em português. Sobre os diversos termos encontrados ver anexo 1.

6 As análises a serem realizadas para conhecer a situação inicial podem variar de caso para caso. Análises típicas no enfoque são as dos problemas, dos envolvidos e afetados, dos objetivos e das alternativas. 
7 O fato de projetos de desenvolvimento sempre conterem dimensões políticas, torna as decisões sobre a melhor estratégia de um projeto mais difíceis e muitas vezes menos objetivas. Daí podem resultar conflitos de objetivos que são difíceis de integrar um só Objetivo do Projeto. Por outro lado, a consideração de vários objetivos apenas adia os conflitos até a fase da implementação. Do ponto de vista gerencial, a definição de um único Objetivo de Projeto é vantajosa.

Na sua versão mais recente do QL, a GTZ introduziu um Objetivo de Desenvolvimento na Lógica de Intervenção, localizado entre o Objetivo do Projeto e o Objetivo Superior. É resultado de uma dificuldade freqüente na definição do Objetivo do Projeto, devido à exigência do método de usar apenas um Objetivo do Projeto. Esse fato pode levar a conflitos de objetivos. Conforme GTZ (1998:28), o Objetivo do Projeto deve descrever a alteração no modo de agir dos grupos-alvo, enquanto o Objetivo de Desenvolvimento deve descrever a situação alterada ambicionada pelos grupos-alvo. Até o momento, outros modelos do QL não seguiram esta recomendação. O Banco Mundial, por exemplo, trata o Objetivo do Projeto sinonimamente com o Objetivo de Desenvolvimento.

Por outro lado, vale destacar que, teoricamente, não existe nenhuma razão para limitar o número dos níveis de uma cadeia lógica. No entanto, seria necessário definir qual a relação entre um nível e outro que se descreve.

Outro conceito que às vezes também é usado sinonimamente é meta, especialmente no planejamento empresarial. Nesse caso, objetivo, resultado ou meta é geralmente quantificado em valor monetário.

9 Berg e Colenso (2000:69) propõem também uma revisão da tradicional forma de descrição da estrutura analítica (WBS - Work Breakdown Structure), acrescentando aos substantivos que descrevem o conteúdo da WBS uma descrição da menor unidade de decomposição dos elementos de um projeto usando verbos para as atividades.

10 Os formatos apresentados em BoITEux (1984) e em BACCARINI (1999) utilizam insumos ou inputs no nível inferior da matriz e não incluem as atividades.

11 Conforme WheatLey (1984:188), não se pode gerenciar o que não pode ser mensurado ("You can't manage what you can't measure")

12 A única exceção encontrada é o modelo apresentado por BACCARINI (1999) que trata apenas da primeira coluna, denominando-a de hierarquia de objetivos. Indicadores, fontes e suposições não são considerados.

13 O modelo da Agência Norueguesa para a Cooperação Internacional NORAD (1996) é o único dos modelos mais completos encontrados que não inclui Fontes de Comprovação.

14 Em inglês é usado o termo Assumptions ou Critical Assumptions. Em português pode ser encontrado o termo Pressuposições. No entanto, este termo pode ser confundido com Pré-requisitos ou Condições Prévias, que são fatores importantes também, mas que precisam ser esclarecidos antes do projeto ser iniciado, enquanto a Suposição Importante tem relevância quando o projeto já está em andamento.

15 O mesmo tipo de suposição é relevante em projetos de desenvolvimento organizacional, pois a maioria das mudanças comportamentais não pode ser imposta.

16 PMI (1996): PMBOK - A Guide to the Project Management Body of Knowledge. Para uma descrição resumida das Áreas de Conhecimento conforme o PMBOK Guide ver anexo 3.

17 O Project Management Institute (PMI) é a maior associação de profissionais da área de gerenciamento de projeto do mundo, com mais de 55.000 associados. Com o propósito de promover o profissionalismo em gerenciamento de projeto, o PMI elaborou o PMBOK Guide como contribuição para a padronização do conhecimento e das práticas em gerenciamento de projeto. Um outro produto do PMI é a certificação de profissionais em gerenciamento de projeto (PMP - Project Management Professional). No Brasil já atuam seis grupos regionais na mesma linha. 
Existem também outras associações profissionais da área na Europa e na Austrália com alguns enfoques diferentes, mas o PMBOK Guide é reconhecido por esses também como uma referência importante.

18 O PMBOK Guide (1996:50) menciona a Logical Framework Analyses apenas no contexto da iniciação de um projeto como um modelo especializado para a tomada de decisões.

O PMBOK Guide encontra-se em revisão. Trata-se basicamente de uma atualização e de um maior alinhamento entre os diversos elementos, mas não deverá haver modificações substanciais. As nove áreas de conhecimento permanecem. A publicação da nova versão está prevista para o final do ano 2000 e o rascunho já está disponível na Internet: www.pmi.org.

20 Para uma descrição mais detalhada em português do conteúdo do PMBOK Guide e da sua aplicação na prática ver, por exemplo, DinsmoRe (1999).

\section{Referências bibliográficas}

BaCCarinı, David. (1999), “The Logical Framework Method for Defining Project Success". In Project Management Journal, v. 30, n. 4, pp. 25-32.

Berg, Cindy e Colensa, Kim. (2000), "Work Breakdown Structure Practice Standard Project - WBS vs. Activities". In PM Network, April 2000, v. 14, n. 4, pp. 69-71.

Borteux, Colbert Demaria. (1985), PERT/COM / ROI e Outras Técnicas de Programação e Controle. Editora LTC, pp. 44-62.

Bolay, F. W. (1993), Planejamento de Projeto Orientado por Objetivos - Método ZOPP. Recife: GTZ.

Comissão das Comunidades Européias. (1993), Manual Gestão do Ciclo do Projecto. Abordagem Integrada e Quadro Lógico. Bruxelas: Comissão das Comunidades Europeias, Série Métodos e Instrumentos para a Gestão do Ciclo de Projecto.

Deutsche Gesellschaft für Technische Zusammenarbeit (GTZ). (1996), Project Cycle Management (PCM) and Objectives-oriented Project Planning (ZOPP). Guidelines. Eschborn: GTZ

. (1998), ZOPP Planejamento de Projeto Orientado por Objetivos. Um Guia de Orientação para o Planejamento de Projetos Novos e em Andamento. Eschborn: GTZ.

Dinsmore, Paul C. (1999). Transformando Estratégias Empresariais em Resultados Através da Gerência por Projetos. Rio de Janeiro: Ed. Qualitymark

Intervention. (s/d), Action Plans, Programme Review \& Control. Versão eletrônicapublicada na Internet. (URL: www.intervention.org)

J ACKson, Bill. (s/d), Designing Projects and Project Evaluations Using The Logical Framework Approach. Versão eletrônica publicada na Internet (URL: www.iucn.org/ themes/eval/english/lfa.htm).

Kohnert, Dirk; Preuss, Hans-Joachim A. e Sauer, Peter (ed.). (1992), Perspektiven Zielorientierter Projektplanung in der Entwicklungszusammenarbeit. Köln: Weltforum Verlag.

Lewis Grant Associates. (s/d), Diversos documentos eletrônicos encontrados na Internet (URL: www.lgausa.com). 
Ministerio de Agricultura de Peru. (1985), El Marco Lógico. Una guía de gerentes para diseñar y evaluar proyectos en forma científica. Lima, Peru.

Norwegian Agency for Development Cooperation (NORAD). (1996). The Logical Framework Approach (LFA). Handbook for objectives-oriented planning. Oslo.

Organizaçãodos EstadosAmericanos (OEA), Secretaria Executiva para oDesenvolvimento InTEGRAL (SEDI). (s/d), Taller para el Diseño, Formulación y Programación de Actividades de Cooperación Solidaria del CIDI.

PfEIFFER, Peter. (1999), "Glossário MPP”. Termos e conceitos de Management de Projetos e Processos. Versão eletrônica. (URL: www.homeshopping.com.br/ mpprio).

. (2000), "Gerenciamento do Ciclo de Projeto". Manual do curso de capacitação para gerentes de projeto. Rio de Janeiro: MPP.

Project M anagement Institute (Pмi). (1996), A Guide to the Project Management Body of Knowledge (PMBOK Guide). Newton Square: PMI Standards Committee.

United Nations Development Program (UNDP). (s/d), Results-oriented Monitoring and Evaluation: A Handbook for Program Managers.

U.S. Agency for International Development (USAID). (1999), Results-Oriented Assistance: a USAID Sourcebook.

Wheatley, Claire-Marie. (1984), "The Logical Framework Approach to Project Planning and Management (ZOPP)". In HaufF, PhSTAR-GASPARY (ed.), Entwicklungspolitik. Probleme, Projektanalysen und Konzeptionen. Saarbrücken: Breitenbach, pp. 187-195.

World Bank. (1996), Designing Project Monitoring and Evaluation. Washington: World Bank, Operations Evaluation Department. (URL: www.worldbank.org).

(1999), Guidelines for Completing the Project Concept Document. (não publicado).

(s/d), "Objectives-oriented Project Planning (ZOPP). Collaborative Decisionmaking: Workshop-based Method". In The World Bank Participation Sourcebook. (URL: www.worldbank.org). 


\section{O Quadro Lógico: um método para planejar e gerenciar mudanças}

Peter Pfeiffer

O Quadro Lógico é um dos instrumentos de planejamento mais difundidos tanto entre as agências internacionais de desenvolvimento quanto em instituições nacionais que lidam com projetos de desenvolvimento. O Quadro Lógico (QL) apóia duas principais funções gerenciais, o planejamento e o controle, mas ele é muito mais do que uma simples ferramenta. Uma vez assimiladas a lógica que o fundamenta e as práticas de trabalho que lhe são associadas, muitas organizações começam a revisar estruturas e procedimentos, a fim de aumentar a eficiência do gerenciamento de projetos por um lado, e a efetividade das melhorias por outro. Este foi o ponto de partida para a sua elaboração e continua sendo a principal razão para a sua aplicação. Hoje, o volume de compromissos de agências de desenvolvimento é estimado em US\$ 200 bilhões em 130 países. A maior parte será canalizada por meio de projetos, e a maioria deles utiliza o QL como metodologia referencial.

A aplicação do QL é mais apropriada, mas não exclusiva, em projetos de desenvolvimento, sejam de caráter público e de cunho social, sejam projetos de desenvolvimento organizacional.

O QL procura definir os principais parâmetros de um projeto em uma matriz que contém quatro colunas e quatro níveis. Nestes 16 campos é preenchida, de forma resumida, a maioria das informações relevantes sobre o projeto, tais como: objetivos, resultados esperados, os respectivos indicadores que estabelecem metas quantitativas e qualitativas, as fontes onde as informações relevantes podem ser encontradas e fatores externos que representam riscos e que precisam ser monitorados.

O QL evidencia as áreas de responsabilidade da gerência do projeto e as áreas de contexto que o influenciam, mas que não podem ser controladas por ele. Com isso, o QL visa mostrar a viabilidade de uma proposta e os fatores críticos de êxito do projeto.

\section{El Marco Lógico: un método para planificar y gerenciar cambios Peter Pfeiffer}

El Marco Lógico es uno de los instrumentos de planificación más difundidos tanto entre las agencias internacionales de desarrollo como en instituciones nacionales que trabajan con proyectos de desarrollo. El Marco Lógico apoya dos de las principales funciones de la gerencia, la planificación y el controle, pero él es mucho más que una simples herramienta. Una vez asimiladas la lógica que lo fundamenta y las prácticas de trabajo que le son asociadas, muchas organizaciones empiezan la revisión de las estructuras y procedimientos organizacionales, en búsqueda de más eficiencia del gerenciamento de proyectos por un lado, y de la efectividad de las intervenciones por otro. Este fue el motivo inicial para su elaboración y continua siendo la principal razón para su aplicación. Hoy día, el volumen de los compromisos de las agencias de desarrollo es estimado en US\$ 200 mil millones en 130 países. La mayor parte será invertido a través de proyectos, y gran parte de ellos utiliza el Marco Lógico como metodología referencial.

La aplicación del Marco Lógico es más apropiada - pero no exclusiva - en proyectos de desarrollo, sean ellos de carácter público y social, ó sean ellos proyectos de desarrollo organizacional.

Peter Pfeiffer

é doutor em Sociologia e Planejamento Urbano e mestre em Sociologia de Desenvolvimento pela Universidade Livre de Berlim,

Alemanha. Profissional em Gerenciamento de Projetos pelo Project Management Institute, EUA. Consultor em Gerenciamento de Programas e Projetos 
El Marco Lógico busca definir los principales parámetros de un proyecto en una

matriz que contiene cuatro columnas y cuatro niveles. Los 16 campos son llenados, en forma resumida, con gran parte de las informaciones relevantes sobre el proyecto, tales como: objetivos, resultados esperados, los respectivos indicadores que establecen metas cuantitativas y cualitativas, las fuentes donde las informaciones relevantes pueden ser encontradas y factores externos que representan riesgos y que necesitan monitoreo.

El Marco Lógico evidencia las áreas de responsabilidad de la gerencia del proyecto y las áreas del contexto que lo influencian, pero que no pueden ser controladas por ella. Así, el Marco Lógico logra demostrar la viabilidad de una propuesta y los factores críticos de éxito del proyecto.

\section{The Logical Framework: a method for planning and managing changes \\ Peter Pfeiffer}

The Logical Framework (also known as Logframe) is one most widely used instruments for planning among the international development agencies as well as the national institutions working with development projects. The Logframe supports two of the main managerial functions, planning and controlling, but it is more than a simple tool. Once assimilated the fundamental logic and the work practices associated with it, many organizations initiate a revision of the organization's structure and procedures, in order to increase the efficiency of their project management on one hand, and the effectiveness of the interventions on the other. This was the starting point for its creation and continues to be the main reason for its utilization. Today, the volume of outstanding commitments of the main development agencies is estimated in US\$ 200 billion in about 130 countries. A big part of it will be channeled trough projects, and most of them use the Logframe as a methodological reference.

The application of the Logframe is most appropriate — but not exclusively — for development projects, whether they have a public character with a social goals, or whether they are organization development projects.

The Logframe seeks to define the main parameters of a project in a matrix, which contains four columns and four levels. These 16 fields are filled in concisely with most of the relevant information about the project, such as: outcomes, outputs, its respective indicators which establish targets in terms of quality and quantity, the means of verification for these information and those external factors which can be hazardous to the project and need to be monitored.

And finally, the Logframe shows the scope of responsibility of the project management and the context and those influences which can't be controlled by management means. Thus, the Logframe seeks to make clear the viability of a proposal and the critical success factors of a project. 